\title{
Procesos deposicionales y antrópicos en el registro holoceno de la Cova de Can Sadurní (Begues, Barcelona, España): aportaciones microestratigráficas
}

\author{
M.M. Bergadà(1), J.M. Cervelló(1), M. Edo ${ }^{(2)}$, F. Antolín ${ }^{(2 \text { y3) y P. Martínez }}{ }^{(2)}$ \\ (1) SERP, Departament d'Història i Arqueologia, Universitat de Barcelona, C/Montalegre 6-8, \\ E-08001 Barcelona, España \\ bergada@ub.edu \\ (2) CIPAG, Col·lectiu per la investigació de la prehistòria i l'arqueologia del Garraf-Ordal, Barcelona, España \\ (3) IPAS, Integrative Prehistory and Archaeological Science, University of Basel, Basel, Suiza
}

\begin{abstract}
RESUMEN
El estudio geoarqueológico y microestratigráfico de la secuencia de la Cova de Can Sadurní (Begues, Barcelona) ofrece una variabilidad de procesos deposicionales de tipo detrítico y antrópico que en determinadas etapas se alternan y repercuten en los procesos diagenéticos localizados. La secuencia cultural del yacimiento va desde el Epipaleolítico hasta época Romana bajo imperial con algunas interrupciones cronoculturales. Durante el Epipaleolítico y Mesolítico los aportes solifluidales son los responsables de la sedimentación. A partir del Neolítico, movimientos de masa y procesos coluvionales son los dominantes. Se distinguen flujos densos principalmente durante el Neolítico antiguo cardial y postcardial inicial; también se localizan pero con menor extensión durante el Neolítico medio postcardial, Neolítico final/Calcolítico y en el Bronce inicial. Los aportes coluvionales no laminados aparecen en el resto de la secuencia. Estos episodios se alternan con fases de estabilidad en el medio en el que la tasa de sedimentación detrítica es menor o casi inexistente y es reemplazada por los aportes procedentes de las actividades de estabulación localizados in situ durante el Neolítico epicardial y postcardial inicial; aunque ya se constaten evidencias desde el Neolítico antiguo cardial. Asociados a estos contextos, los procesos hidromórficos se acentúan dando lugar a la formación de vivianita, fosfato de hierro, propia de lugares reductores con un gran contenido orgánico.
\end{abstract}

Palabras clave: coluvión, Holoceno, karst, micromorfología, rediles.

\section{Depositional and anthropic processes in the Holocene record of the Can Sadurni cave (Begues, Barcelona, Spain): microstratigraphic contributions}

\begin{abstract}
The geoarchaeological and microstratigraphic study of the Can Sadurní cave sequence (Beques, Barcelona) reveals the presence of detrital and anthropogenic depositional processes, alternating at certain stages. These influenced the location of the diagenetic processes. The cultural sequence of the site ranges from Epipaleolithic to Late Roman Empire, with some chronocultural interruptions. During the Epipaleolithic and Mesolithic, solifluction processes were responsible for sedimentation. From the Neolithic, mass wasting and colluvial processes were dominant. Dense flows are distinguished mainly during the Cardial Early Neolithic and Early Postcardial. This type of contribution is also present to a lesser extent during the Postcardial Middle Neolithic, Late Neolithic/Chalcolithic and Early Bronze Age. Non-laminated colluvial inputs appear in the rest of the sequence. These episodes alternate with periods of stability, in which the rate of detrital sedimentation is lower or almost non-existent. This is replaced by the presence of in situ stabling areas during the Epicardial and Early Postcardial Neolithic, although evidence is detected from the Cardial Early Neolithic. Associated with these contexts, hydromorphic processes are accentuated leading to the formation of vivianite -an iron phosphate mineral- typical of a reducing medium with high organic matter.
\end{abstract}

Key words: colluvium, Holocene, karst, micromorphology, stabling areas. 
Bergadà, M.M., et al., 2018. Procesos deposicionales y antrópicos en el registro... Boletín Geológico y Minero, 129 (1/2): $251-284$

\section{ABRIDGED ENGLISH VERSION}

\section{Introduction}

The aim of this paper is to analyze the formative and diagenetic processes of the Holocene sequence of the Can Sadurni cave in order to obtain the evolutionary history of the record. This site contains one of the longest diachronic sequences of the northeast peninsular, ranging from the Epipaleolithic to Late Empire. This sequence emphasizes the Neolithic record, especially its early phase (Edo et al., in press a; Edo et al., in press b).

The excavated area of the cave consists of $51 \mathrm{~m}^{2}$ of which four $\mathrm{m}^{2}$ correspond to a sondage that began in 1997 (Fig. 1) to analyse the diachronic sequence of the site and provide the sedimentary characterization of the cavity (Edo et al., 2011). Twenty-one archaeological levels have been recorded (Fig. 2), which frame the chronocultural evolution of the sequence from archaeological materials (Edo et al., 2011; Edo et al., in press a; Edo et al., in press b); as well as their radiocarbon dates (Table 1) and numismatic record for the full historical stages.

\section{Geographical, geological context and karst formation}

The Can Sadurni cave is located in the town of Begues (Baix Llobregat, Barcelona). It is in an early stage of karstification of the massif. It is located about $421 \mathrm{~m}$ ASL on the northern margin and $40 \mathrm{~m}$ above the plain of Begues, an increased karst depression (paleo-polje) surrounded by a highly karstified relief.

The geological map of the surroundings of the Can Sadurni cave and Begues shows the complexity of the Garraf Massif (Fig. 3). The landscape characterizing the massif consists of dolomites and limestone of the Jurassic and Cretaceous, within which a karst has developed with typical surface attributes and hundreds of underground cavities.

The Can Sadurni cave has the characteristics of an old channel located in the saturated zone of the karstic system (Fig. 4a). Its evolution is marked by openness to the outside, with evidence of clastic collapse and debris cone blocks introducing finer materials going inward. The blocks form a steep ramp into the cave and in the front area of the prism there is a significant detrital sedimentary deposit comprising the sequence that is the object of this paper (Fig. $4 b$ ).

\section{Methods}

The methodology consisted of stratigraphic-sedimentary field descriptions and micromorphological analysis of levels comprising the sequence of the site (Figs. 5a, 5b, 5c, 5d, 5e and 5f).

The micromorphological analysis was completed with scanning electron microscopy (ESEM-EDX) in backscattered electron (BSE) mode and microprobe analyses on thin sections, carried out by the Scientific and Technological Centre at the University of Barcelona (CCiT-UB).

\section{Results: stratigraphic and sedimentary sequence and micromorphological analysis}

Fourteen levels have been distinguished to date, with a thickness of over $400 \mathrm{~cm}$ (Fig. 1 and Figs. 6a, 6b and 6c). The micromorphological descriptions appear in the attached tables (Tables 2, 3, 4, 5, 6 and 7). Twenty-six microfacies (Table 8) have been documented throughout the sequence.

\section{Discussion}

The discussion will be focused primarily on the detrital and anthropic formation and depositional processes. The depositional processes of detrital origin that caused the filling of the site are: solifluction, colluviation and diffuse runoff processes.

The solifluction processes are localized in the Mesolithic and Epipaleolithic sequences - CS XIV (mfs. 26 and 25) and CS XIII (mfs. 24 and 23) (Figs. 7a, 7b, 7c, 7d, 7e and 7f).

The colluviation processes are responsible for most of the sedimentary record. There are two types:

- colluvium with dense flows in which the block and pebble fraction dominates: CS.XII (Cardial Early Neolithic), CS.IX (Early Postcardial Neolithic) and CS.VII (Postcardial Middle Neolithic); in others the extension may not cover the entire cavity and the fraction size is considerably reduced as in: CS.V.2. (Late Neolithic/Chalcolithic) and CS.IV.2. (Early Bronze). 
Bergadà, M.M., et al., 2018. Procesos deposicionales y antrópicos en el registro... Boletín Geológico y Minero, 129 (1/2): 251-284

- unlaminated colluvium where silt loam matrix predominates relative to the coarse fraction.

Some contributions are of weak intensity, such as: CS.XI (mf. 20, Late Cardial Neolithic) (Fig. 8), CS.X (mfs. 18 and 19, Epicardial Neolithic) and CS.VIII (mf. 12, Early Postcardial Neolithic) where instead there is an increase in CS.XI (mfs. 21 Late Cardial Neolithic); CS.V.1 (mfs. 5 and 6, Late Neolithic/Chalcolithic); CS.III (mfs. 2 and 3, Ibero-Roman Epoch), sometimes with erosive contacts such as CS.VI (mf. 7, Postcardial Middle Neolithic).

Some of these deposits, such as CS.IV.1 (mf. 4, Late Bronze), indicate a large water input, demonstrated by the more clay-rich groundmass and increased vesicular porosity, indicator in this case of liquefaction (Bertran and Texier, 1999). In the most recent level CS.I (mf. 1, Late Empire), the colluvium is mixed with phosphate nodules probably of excremental origin or human activity, although it is an episode with relatively recent intrusions.

Diffuse runoff processes are not widespread and are located in the mfs. 10 and 8 CS.VIII (Early Postcardial Neolithic) (Fig. 11d).

The sedimentation generated by human activity is strongly present in this cave with animal stabling practices (ovicaprids and cattle).

It is during the Epicardial Neolithic (CS. X; 15, 14, 13 and 12 layers) when these practices are intensified. There is a general decrease in colluvium and an increase in pastoral components (Figs. 8a, 8b, 8c, 8d and 8e), in some areas with traces of combustion at the end of the sequence (Figs. 9a, 9b, 9c, 9d and 9e).

An interesting aspect is the presence of vivianite (iron phosphate) in the deposit (Figs. 10a and 10b); for its formation a reducing environment with high organic matter content is necessary. In our case this comes mainly from the droppings and perhaps liquid waste from stabling animals.

Later, during the Early Postcardial Neolithic corresponding to CS.VIII (layer 11) the cavity is used for stabling purposes again. The detrital sedimentation decreases significantly and layers of phytoliths and organophosphate droppings appear.

These are distinguished by the presence of layers composed of horizontal and sub-horizontal phytoliths with varied morphologies, and by excrements without traces of combustion (Figs. 11a, 11b, 11c, 11e and 11f). Their composition suggests that some might correspond to cattle and other ovicaprids.

In the Postcardial Middle Neolithic chronocultural horizon, no microstratigraphic evidence of pastoral activity is detected in the cave.

\section{Conclusions}

The microstratigraphic study of the Can Sadurni cave has allowed us to define the sedimentary sequence distinguishing the detrital input and the contributions generated by human activity of a pastoral type.

The sequence with higher resolution offered by the site is the Neolithic with a significant rate of detrital and anthropogenic sedimentation accompanied by an extensive battery of radiocarbon dating.

Its analysis has enabled us to contrast alternating cumulative episodes (mass movements and colluvium from the slopes erosion and scree) with episodes of stability in the middle coinciding with the main pastoral activity in the site during the Early Postcardial and Epicardial Neolithic.

Stabling phases identified in the site disclose the use of the cavity as a byre, primarily for ovicaprids and cattle.

The burning of the residues is recurrent but not in the whole area of the cavity; it should be noted that the colluvial and runoff processes that were present during and after the occupation have altered the deposits.

From the Postcardial Middle Neolithic there is a decrease in the contribution of stabling animals in the cavity, possibly because of a change in the pastoralism strategy in the area. The sequence continues with less important detrital cumulative processes to the Late Roman Epoch.

In short, we believe the Can Sadurní cave opens up new possibilities in the study of the sedimentary and climatic evolution of the Holocene and pastoral strategies in the Garraf Massif.

\section{Introducción}

El objetivo de este trabajo es analizar los procesos formativos (detríticos y antrópicos) y diagenéticos de la secuencia holocena de la Cova de Can Sadurní para obtener la historia evolutiva del depósito.

Este yacimiento constituye uno de los registros con la secuencia diacrónica más prolongada del Noreste peninsular, iniciándose por los datos disponibles hasta el momento en el Epipaleolítico y llega a época Romana bajo imperial. De esta secuencia destaca el registro Neolítico especialmente su fase antigua (Edo et al., 2011; Edo et al., en prensa a; Edo et al., en prensa b).

La cavidad se conoce arqueológicamente desde 1945 pero no se realizaron intervenciones hasta el año 
1978 que han continuado de forma ininterrumpida hasta la actualidad bajo la dirección de uno de los firmantes de este artículo (M.E.) junto a Anna Blasco y Pepa Villalba vinculados a la Universitat de Barcelona y que posteriormente se añadieron dos de nosotros, P.M. de la misma universidad y F.A. de la Universidad de Basilea.

Se han realizado intervenciones en el yacimiento
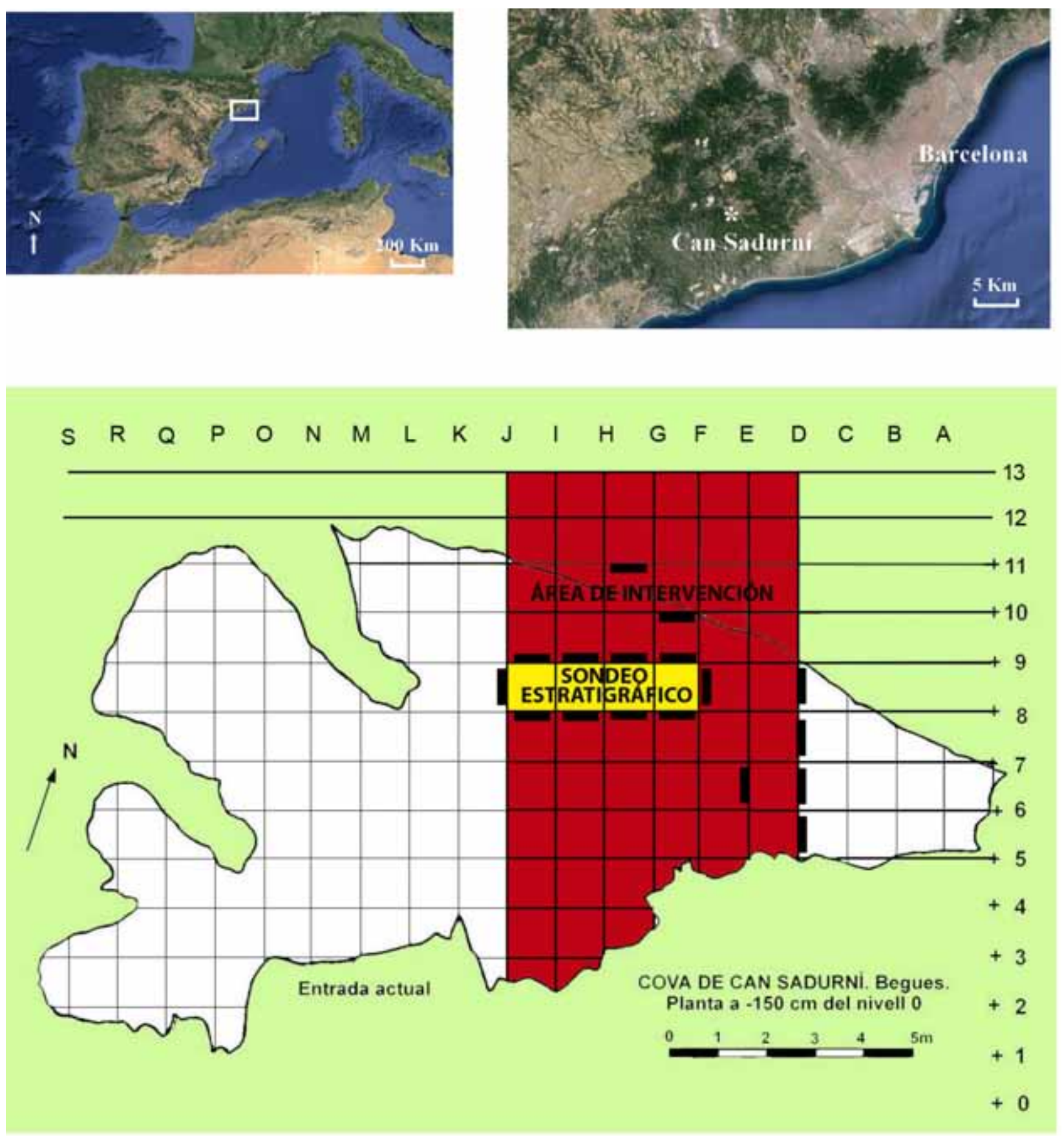

- - Muestreo micromorfológico

Figura 1. Situación geográfica de la Cova de Can Sadurní (Begues, Barcelona) y planta de la cueva. Cuadrícula de excavación: en rojo la zona de intervención y en amarillo el sondeo. Localización del muestreo micromorfológico.

Figure 1. Geographical situation of the Can Sadurní cave (Begues, Barcelona) and cave plan. Excavation grid squares: excavated areas in red and the sondage in yellow. Location of the micromorphological sampling. 
en dos ámbitos: en el exterior de la cavidad denominado "terraza exterior" de unos $400 \mathrm{~m}^{2}$ en el cual se localizaron ocupaciones del Neolítico postcardial junto a silos; y en el interior de la cueva, que constituye el sector principal y que es el objeto de nuestro estudio.

La superficie excavada de la cueva es de $51 \mathrm{~m}^{2}$ de los cuales $4 \mathrm{~m}^{2}$ corresponden a un sondeo que se inició en 1997 (Fig. 1) con el objetivo de establecer la secuencia estratigráfica y diacrónica del yacimiento (Edo et al., 2011). Los datos que se disponen desde el Epipaleolítico hasta el Neolítico postcardial inicial se han obtenido sólo del sondeo.

Se han registrado 21 capas arqueológicas (Fig. 2), que enmarcan la evolución cronocultural del yacimiento a partir de los materiales arqueológicos (Blasco et al., 2005a; Blasco et al., 2005b; Edo et al., 2011; Edo et al. en prensa b); así como, por sus dataciones radiocarbónicas (Tabla 1) y por su registro numismático para las etapas plenamente históricas, como la capa 5 fechada en el siglo II d.C. correspondiente a la etapa alto imperial y la capa 4 del siglo IV d.C. de época Romana bajo imperial; aunque en este último nivel hubo intrusiones de etapas posteriores.

El registro finaliza con las capas 3,2 y 1 de época reciente, mediados de la década de los años 40 del siglo pasado, merece resaltar el uso de la capa 2 para el cultivo del champiñón en la cavidad (Edo et al., 2011).

\section{Contexto geográfico, geológico y formación kárstica}

La Cova de Can Sadurní se ubica en pleno macizo del Garraf en el municipio de Begues (Baix Llobregat, Barcelona). La cueva se halla situada a unos doscientos metros al noreste de la masía de Can Sadurní de la cual toma su nombre, en la vertiente meridional del denominado $\mathrm{Pla}$ de Sots, que tiene una altura de 549 $\mathrm{m}$, en la zona del Pla d'Ardenya del macizo del Garraf (Edo et al., 2011).

Esta cavidad es una forma kárstica perteneciente a un estadio antiguo de la karstificación de dicho macizo. Se sitúa a 421 m s.n.m. en el margen septentrional y a unos $40 \mathrm{~m}$ por encima del llano de Begues, depresión kárstica mayor (paleo-polje) rodeada de relieves muy karstificados.

El macizo del Garraf es un fragmento de la unidad estructural de la Cordillera Costero - Catalana, que forma un horst elevado entre el sistema de fosas litorales y la fosa del Penedés. Se localiza al sur del área metropolitana de Barcelona, entre el valle y el delta del río Llobregat, la depresión del Penedés y la costa mediterránea. Garraf es un segmento de la alineación

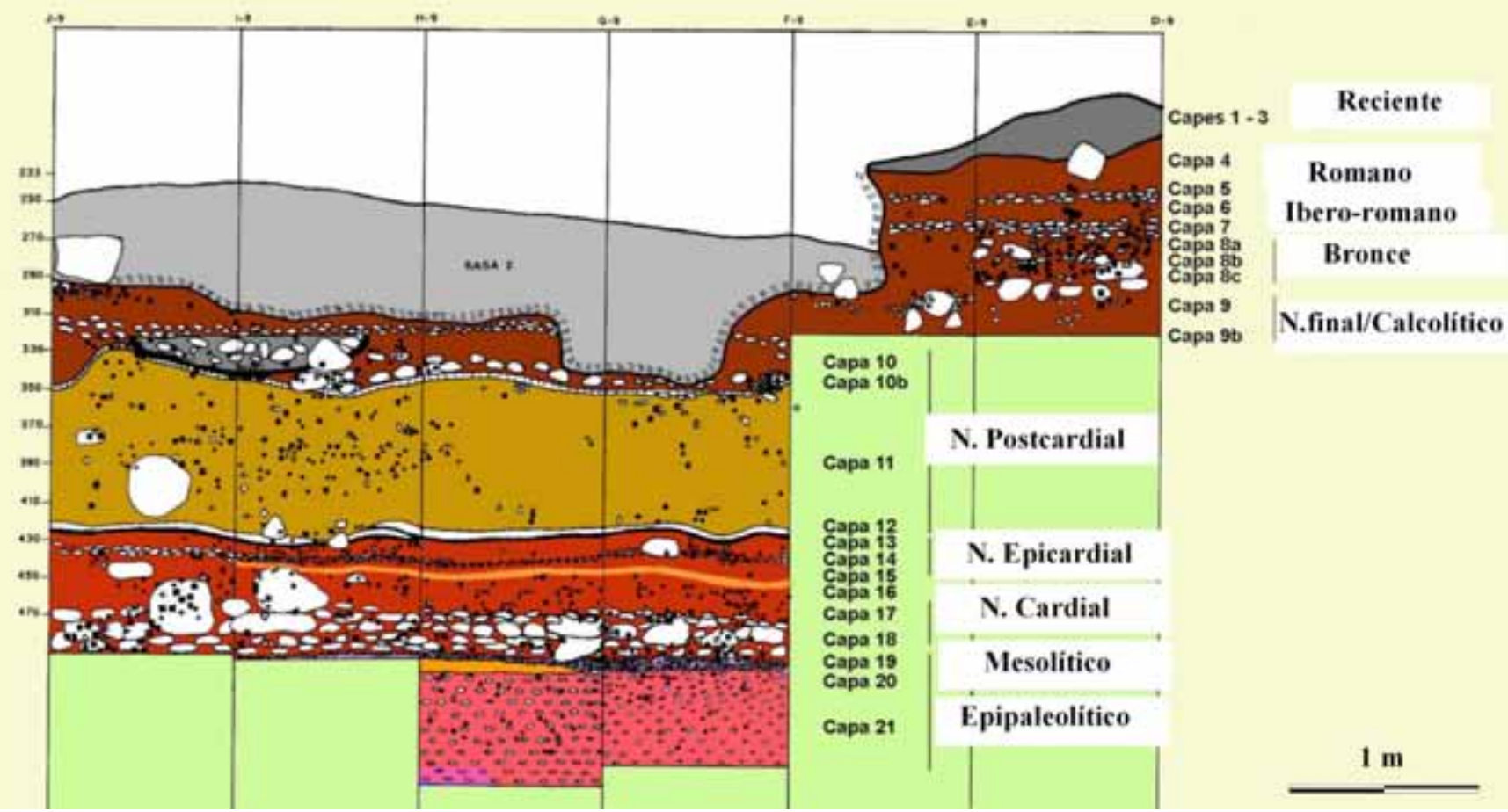

Figura 2. Secuencia estratigráfica arqueológica de la Cova de Can Sadurní. Perfil J/D - 9 y orientación O - E.

Figure 2. Archaeological stratigraphic sequence of the Can Sadurní cave. Profile J/D - 9 and west - east facing. 
de las sierras litorales catalanas y forma un extenso conjunto montañoso litoral que se alza $600 \mathrm{~m}$ sobre las playas de Castelldefels y de Sitges.

El mapa geológico de los alrededores de la Cova de Can Sadurní y de Begues nos muestra la comple- jidad de la geología de Garraf (Fig. 3). En la base del macizo, hacia el valle y el delta del Llobregat aparece un zócalo paleozoico metamórfico sobre el que se sitúa una potente cobertura mesozoica, fracturada intensamente por la tectónica alpina. El paisaje que

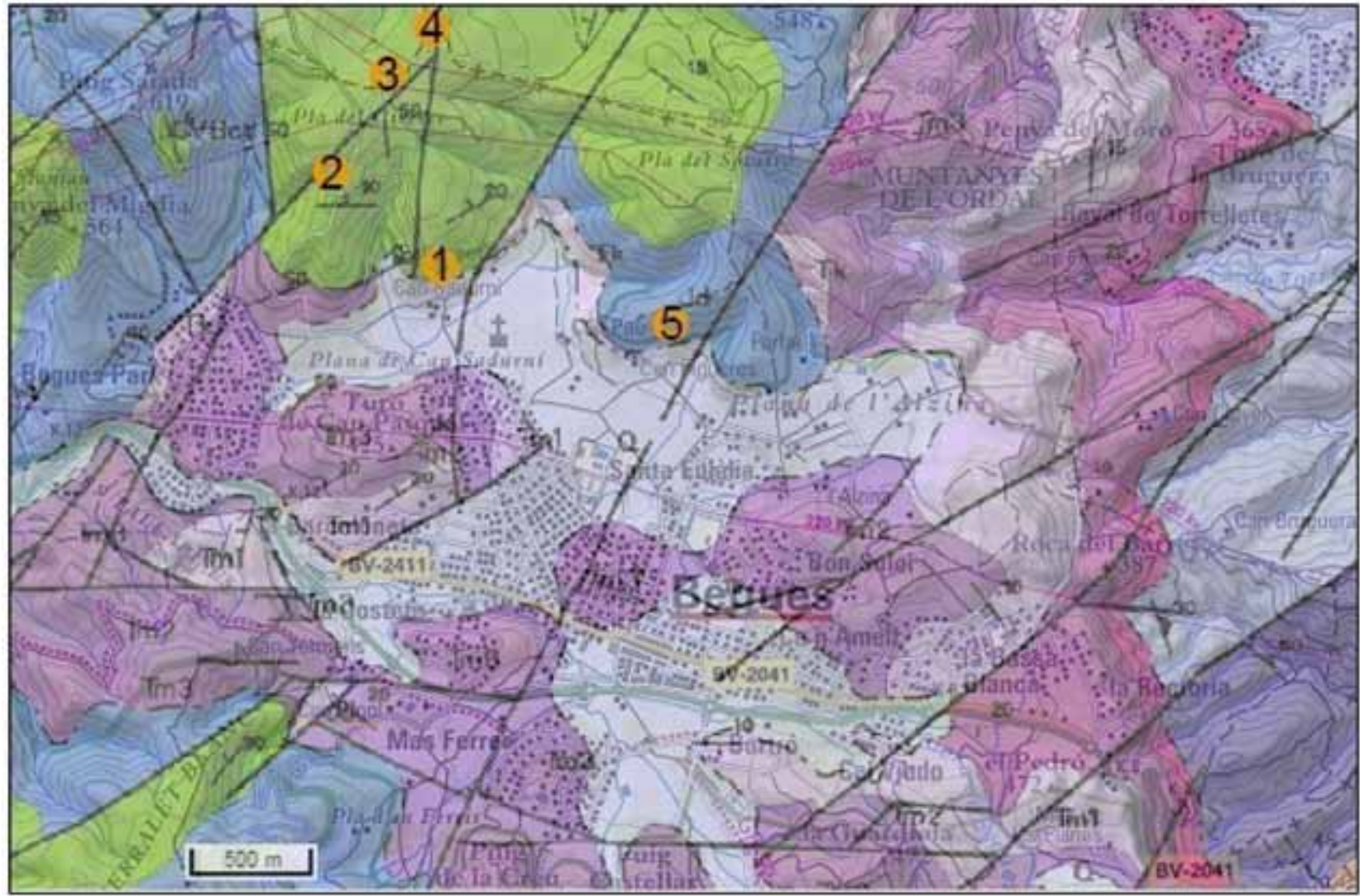

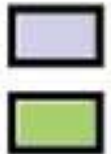

Cunternario. Holoceno.

Aluviones de gravas, arenas y limos.

Cretácico inferior.

Calizas con intercalaciones dolomiticas.
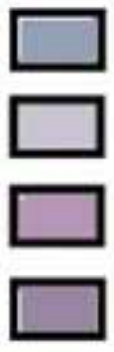

1

2

3
Jurásico-Cretácico Inferior.

Dolomias y calizas.

Triásico Superior. Keuper.

Margas y calizas margosas.

Triàsico Medio-Superior. Muschelkalk Superior.

Dolomias y calizas.

Triàsico Medio. Muschelkalk Medio.

Areniscas y arcillas.

\section{Cova de Can Sadumi}

Avene de Can Sadurni

Dolina y Avenc de I'Alzina Gran
Triásico Medio. Muschelkalk Inferior.

Calizas micriticas y dolomias.

Triásico Inferior. Buntsandstein.

Areniscas siliceas $y$ arcillas.

Triásico Inferior. Buntsandstein.

Conglomerados basales silicicos.

Silurico-Devoniano Inferior.

Calizas nodulosas y pizarras sericiticas.

Silúrico,

Pizarras ampeliticas, filitas y sericitas.

Cambroordovicico.

Pizarras micaciticas y pizarras arenosas.

4 Dolina y Avencs de Les Alzines

5 Cova de Can Figueres

Base cartográfica. ICGC. Mapa geológico 1:50.000

Figura 3. Mapa geológico y situación de los yacimientos citados en el texto.

Figure 3. Geological map and location of the sites cited in the text. 
caracteriza el macizo está formado por las dolomías y calizas del Jurásico y del Cretácico en cuyo seno se ha desarrollado un karst con todos los atributos de modelado superficial y centenares de cavidades subterráneas.

El macizo del Garraf está formado por altiplanos surcados por valles y cañones, con depresiones mayores (poljes), campos de dolinas en las partes superiores, simas y cuevas que recibían las aguas de infiltración y formaban ríos subterráneos que desembocaban en la misma línea de costa, después de atravesar subterráneamente todo el macizo.

Los relieves circundantes a los poljes son sectores muy karstificados. La Cova de Can Sadurní, como la vecina Cova de Can Figueres, se abre al pie de estos relieves, casi en su contacto con el llano de Begues. En las partes superiores, tanto en las cabeceras de la red hidrográfica que se encaja en las vertientes, como en los campos de dolinas que ocupan los llanos superiores, se abren cavidades verticales (las simas de Can Sadurní, L'Alzina Gran y Les Alzines, entre otras) (Daura et al., 2014). Mientras las cuevas inferiores se formaron en la zona saturada del sistema kárstico, las simas superiores son formas de la zona de infiltración del karst.

En el macizo del Garraf impera la verticalidad de las cavidades, las cuevas son escasas y de dimensiones reducidas. Los sedimentos introducidos desde el exterior por las fisuras y simas son habituales. Cuando hay un conducto con cierto desarrollo horizontal al pie de un acceso vertical, se desarrollan conos de deyección con materiales procedentes del exterior que van progresando hacia el interior, se trata de depósitos detríticos muy heterométricos.

La Cova de Can Sadurní presenta las características de un antiguo conducto situado en la zona saturada del sistema kárstico (Fig. 4a). Su evolución, similar a otras cavidades del sector, viene marcada por una serie de etapas:

1. Formación de la cavidad a partir de discontinuidades en la roca caliza, planos de estratificación y microestructuras tectónicas subverticales. A mayor escala se observa la alineación de cavidades siguiendo las directrices estructurales de la tectónica alpina fini-oligocena.

2. Modelado de disolución en paredes y techo como resultado del régimen inundado de la cavidad. Grandes cavitaciones en las paredes y cúpulas de disolución en el techo.

3. Descenso general del nivel de base del karst y nueva posición de la cavidad en la zona de infiltración, no saturada, del sistema kárstico. En el interior de los conductos se acumula la fracción no soluble, limos y arcillas rojas endurecidas, de los procesos de karstificación superficiales, especialmente activos bajo la cubierta edáfica. Se localiza en la parte oriental de la sala de la cueva.

4. Precipitación de espeleotemas en la cavidad en forma de coladas parietales y edificios estalagmíticos.

5. Apertura, o ampliación de la apertura, de las cavidades al exterior, formación de colapsos clásticos, conos de deyección con bloques que progradan hacia el interior e introducción de materiales más
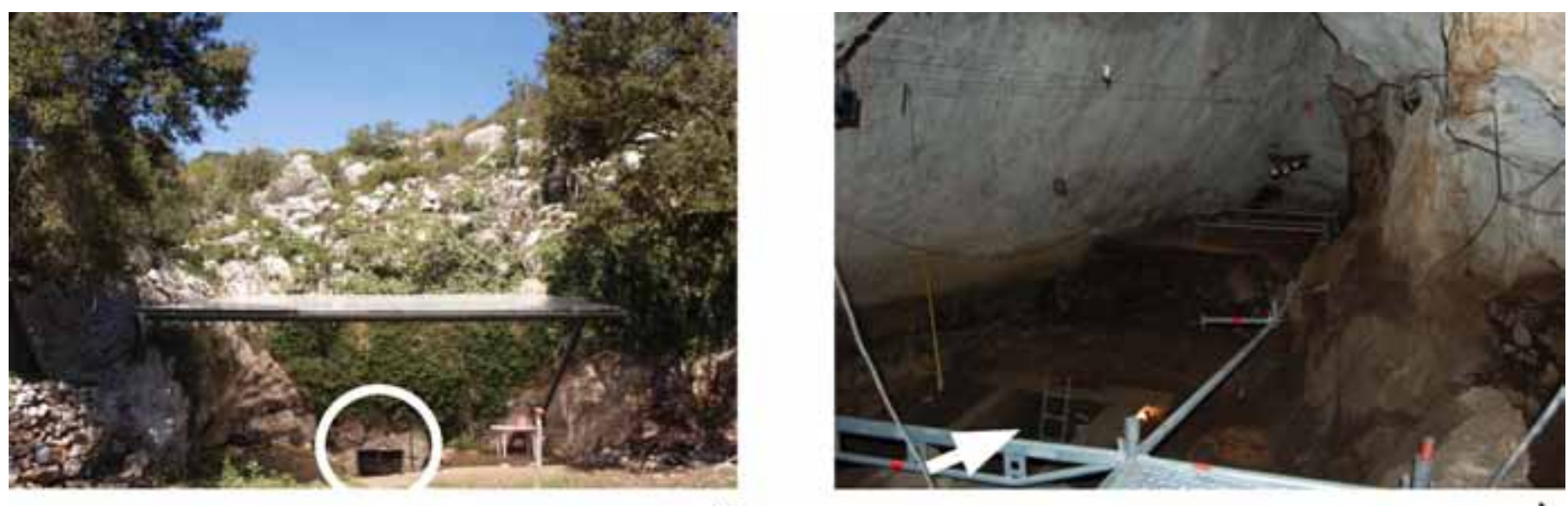

Figura 4. Cova de Can Sadurní (Begues, Barcelona). a. Entrada de la cavidad. b. Vista general del conducto de la cavidad y del depósito sedimentario, con una flecha el sondeo.

Figure 4. Can Sadurní cave (Begues, Barcelona). a. Cave Entrance. b. Overview through the cavity and sedimentary deposit, with an arrow to the sondage. 
Bergadà, M.M., et al., 2018. Procesos deposicionales y antrópicos en el registro... Boletín Geológico y Minero, 129 (1/2): $251-284$

finos. Los bloques forman una rampa pronunciada hacia el interior de la cueva y la zona frontal de este prisma detrítico hay un importante depósito sedimentario que comprende la secuencia objeto de este artículo (Fig. 4b).

6. Cubrimiento de los sedimentos por coladas y estalagmitas, tal y como observamos en cavidades próximas a Can Sadurní (la cova de Can Figueres, por ejemplo).

\section{Metodología de estudio}

La metodología que hemos utilizado ha consistido en la descripción estratigráfico-sedimentaria de campo y en la aplicación de la micromorfología a los niveles que comprende la secuencia del yacimiento. Para realizar dicho estudio nos hemos basado principalmente en los perfiles facilitados por el sondeo, concretamente $\mathrm{F}-8$ y J-8; así como, también en J-F/7 y JF/9 especialmente para el tramo inferior de la secuencia. En cambio, para el tramo superior, concretamente el registro de Prehistoria reciente e histórico, hemos tenido en cuenta el perfil D/5-6-7-8-9. También se ha analizado algunos otros sectores de algunos niveles como las inhumaciones de los individuos 1 y 2 correspondientes al Neolítico postcardial de los cuadros F-9 y G-11; así como, también en el cuadro E-6.

El protocolo que hemos seguido para la extracción de muestras, un total de 29, consiste en la introducción del sedimento en unas cajas recubiertas de yeso que nos han permitido obtener bloques sin alterar la estructura y disposición del relleno sedimentario (Bergadà, 1998) (Figs. 5a, 5b, 5c, 5d, 5e y 5f). Los bloques fueron secados al aire y después en la estufa a $40{ }^{\circ} \mathrm{C}$ durante 48 horas para evitar recristalizaciones. Se impregnaron con una resina de poliestireno. Se cortaron en tablillas de pocos centímetros de grosor y finalmente se realizaron las láminas delgadas, en total 2 por cada bloque, de $13,3 \times 5,5 \mathrm{~cm}$ y $20 \mu \mathrm{m}$ de grosor según el protocolo de Benyarku and Stoops (2005). Se utilizó el microscopio óptico petrográfico bajo unos aumentos entre $25 x$ y $400 x$ con luz polarizada plana (LPP), luz polarizada cruzada (LPX) y con luz oblicua incidente (LOI); finalmente, para la descripción hemos seguido los criterios utilizados por Bullock et al., (1985) y Stoops (2003).

El análisis micromorfológico ha sido completado con el microscopio electrónico de barrido (ESEM) con detectores de electrones retrodispersados (BSE) y microanálisis $\mathrm{RX}$ (EDS) realizado en los Centros Científicos y Tecnológicos (CCiT) de la Universitat de Barcelona.

\section{Secuencia estratigráfica y sedimentaria}

Para la obtención de la secuencia hemos utilizado preferentemente para el tramo inferior los perfiles de los cuadros J-F/8 del sondeo (Fig. 5b, Figs. 6a y 6b); así como, para el tramo superior el perfil de los cuadros D-5/9 del yacimiento (vid. Fig. 1 y Fig. 6c). A partir de esos perfiles hemos realizado el trabajo de campo y la toma de muestras. Se han distinguido 14 niveles que alcanzan por el momento más de $400 \mathrm{~cm}$ de potencia. Hemos de hacer constar nuestra seriación numérica de techo a muro a la hora de definir los niveles litoestratigráficos; ya que aún no se ha localizado la roca del sustrato. Los niveles identificados de muro a techo son:

- Cantos de caliza con limos arcillosos. CS.XIV. Potencia vista $53 \mathrm{~cm}$. Compuesto por cantos de caliza micrítica subangulosa de 1 a $5 \mathrm{~cm}$ con bloques dispersos. Hacia el techo aparecen bloques en los cuales el eje máximo es perpendicular a la dirección del depósito. La matriz es de limos arcillosos con arenas de color marrón (7,5YR 5/4). Aparecen restos carbonosos y fauna entre la matriz. La geometría del depósito con tendencia tabular y con una ligera pendiente Norte-Noroeste. Arqueológicamente corresponde a la capa 21 (Epipaleolítico).

- Limos arcillosos con cantos. CS.XIII. Potencia entre $9 \mathrm{~cm}$ y $35 \mathrm{~cm}$. Se caracteriza, especialmente en el perfil J-8, por una cierta alternancia de gravas y cantos de calibre pequeño $(1-2 \mathrm{~cm})$ de morfología subangulosa a subredondeada con cierta clasificación con una matriz de limos arcillosos con arenas de color marrón anaranjado (5YR 4/4). Parece intuirse más presencia de carbones entre la fracción gruesa. Hacia el techo domina la matriz. El contacto con respecto a CS.XIV está marcado por bloques que nos documenta un hiato entre ambos niveles.

Se correlaciona con las capas 20 y 19 (Mesolítico de muescas y denticulados).

- Bloques y cantos. CS.XII. Potencia media de 30 a $35 \mathrm{~cm}$. Está constituido por un $90 \%$ de bloques, de un tamaño entre 15 y $20 \mathrm{~cm}$, y cantos de caliza de morfología subangulosa con una pendiente hacia el Norte. La matriz está formada por limos arcillosos con arenas de color marrón oscuro (5YR 4/2) y abundan restos óseos y carbonosos. Entre los intersticios de los bloques aparece el material detrítico con cierta clasificación. En el interior del sondeo presenta una pendiente NNW entre el $14 \%$ y $5 \%$ según el perfil. Está en discontinuidad estratigráfica con respecto a CS.XIII. 


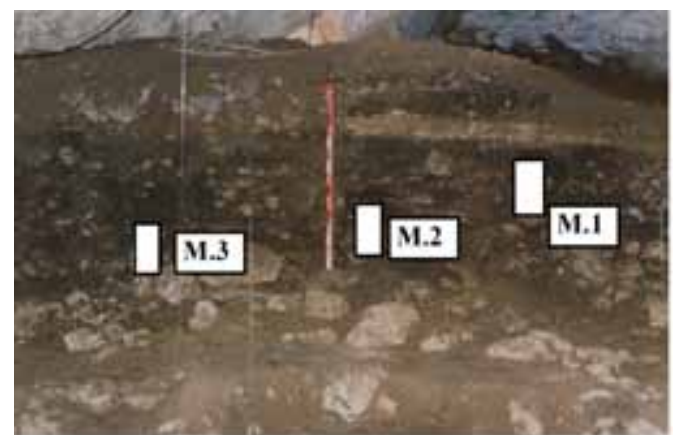

$\mathbf{a}$

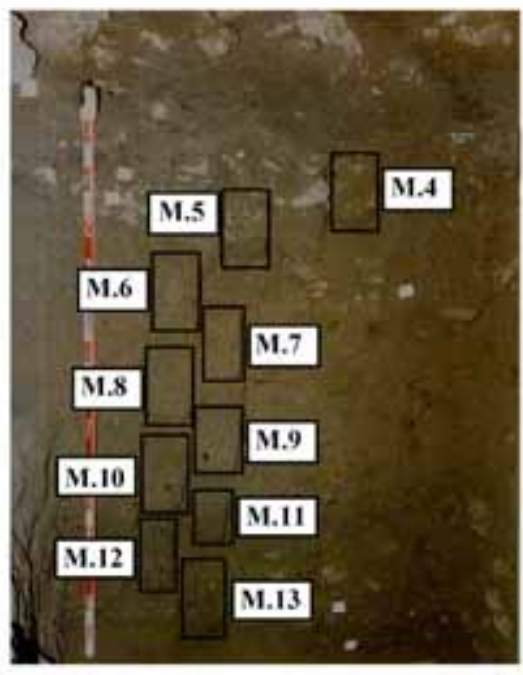

b

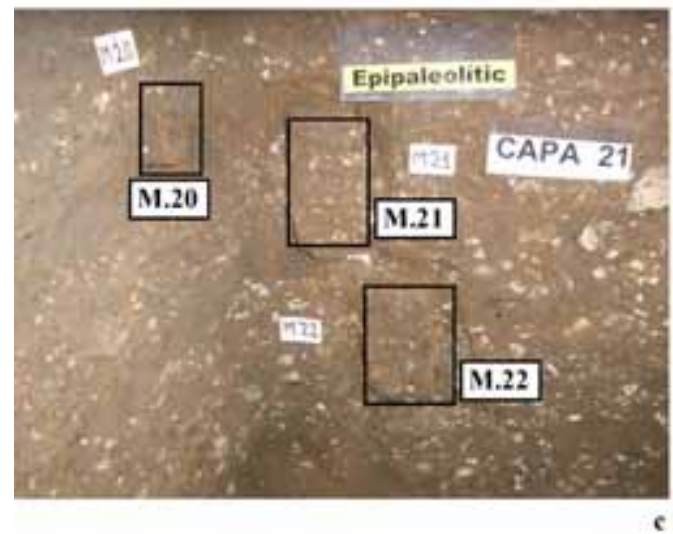

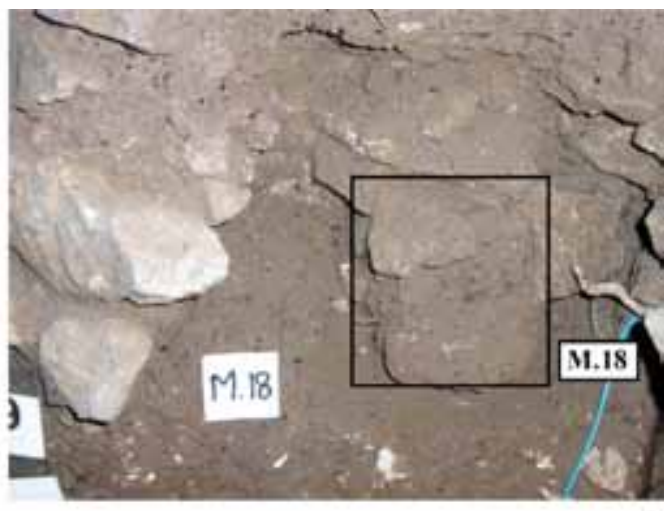

d
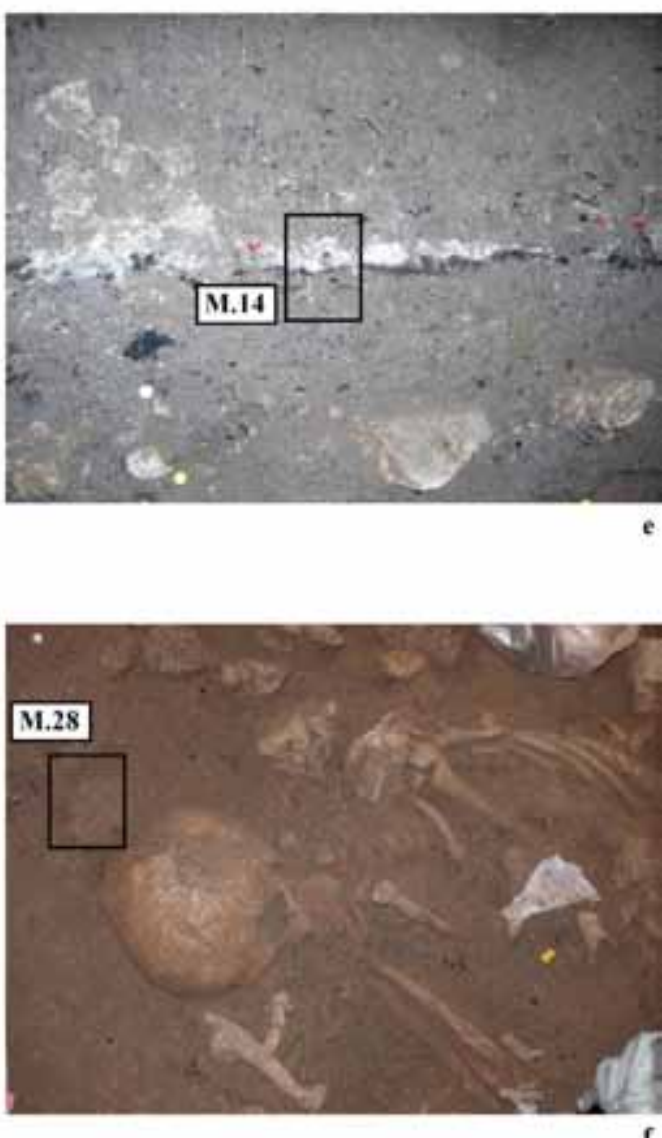

Figura 5. Muestreo micromorfológico.

a. Perfil D/5-8. Detalle del muestreo de la secuencia del Bronce a época Romana (Bajo Imperio). CS.IV- CS.I.

b. Perfil F-8. Detalle del muestreo. Secuencia del Neolítico postcardial al Neolítico final/Calcolítico. CS.VIII - CS.V.

c. Perfil F-8/F-9. Detalle del muestreo de la secuencia Epipaleolítica CS.XIV.

d. Perfil G-8/F-8. Detalle del muestreo del Neolítico antiguo cardial. CS.XII.

e. Perfil G-8/H-8. Muestreo área de redil. Neolítico epicardial/postcardial. CS.X.

f. Cuadro F-9. Inhumación 1. Neolítico postcardial inicial CS.VIII.

Figure 5. Micromorphological sampling.

a. D/5-8 profile. Detail of the sampling from Bronze to Late Empire. CS.IV - CS.I.

b. F-8 profile. Detail of the sampling. From Postcardial Neolithic to the Late Neolithic/Chalcolithic. CS.VIII - CS.V.

c. F-8/F-9 profile. Detail of the Epipaleolithic sequence sampling CS.XIV.

d. G-8/F-8 profile. Detail of the Cardial Early Neolithic CS.XII.

e. G-8/H-8 profile. Stabling area sampling. Postcardial/Epicardial Neolithic CS.X.

f. F-9 grid-square. Inhumation 1. Early Postcardial Neolithic. CS.VIII. 

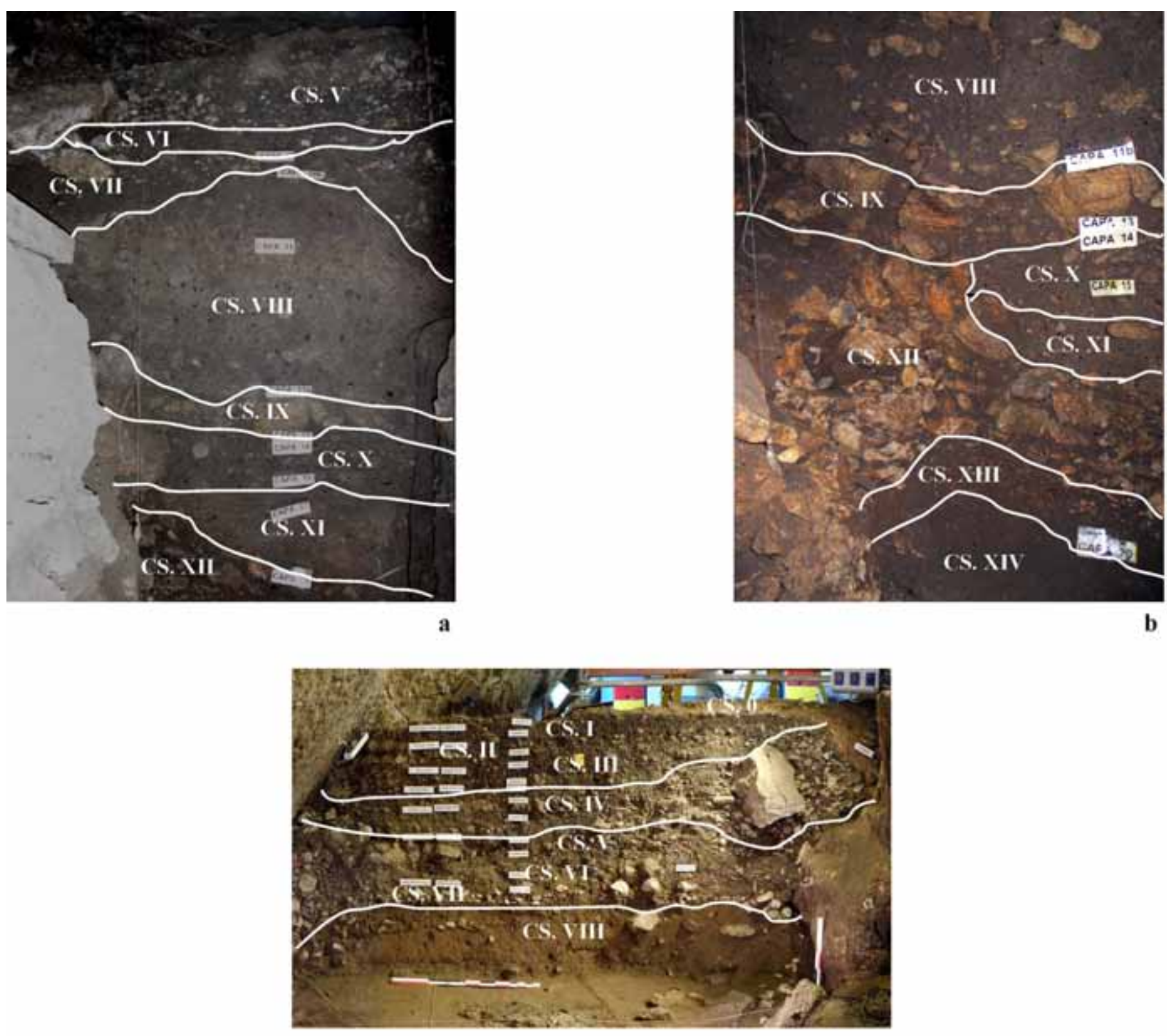

Figura 6. Perfiles estratigráficos. Distinción de los niveles identificados en el campo.

a. Perfil sondeo J-8. CS.XII - CS.V.

b. Perfil cuadro J/8-7. CS.XIV - CS.VIII.

c. Perfil D/5-8. CS.VIII - CS.0.

Figure 6. Stratigraphic profiles. Distinction of the levels identified in the field.

a. J - 8 Probe profile. CS.XII - CS.V.

b. J/8 - 7 Grid-square. CS. XIV - CS. VIII.

c. D/5-8 profile. CS.VIII - CS.O.

Se relacionaría con la capa 18 (Neolítico antiguo cardial).

- Arenas limosas. CS.XI. Potencia media $19 \mathrm{~cm}$. La matriz está compuesta por arenas limosas de color pardo (5YR 4/3) con algunos cantos $y$ bloques dispersos. Disminuye considerablemente la fracción gruesa con respecto al anterior nivel. Localmente aparece una estructura de bloques subangulares. Hacia el techo hay un dominio de la fracción limosa que se localiza en 
Bergadà, M.M., et al., 2018. Procesos deposicionales y antrópicos en el registro... Boletín Geológico y Minero, 129 (1/2): 251-284

\begin{tabular}{|c|c|c|c|c|c|c|}
\hline Capa & Muestra & Laboratorio & Datación BP & CalBP p $(95 \%)$ & CalBC & Periodo \\
\hline 6 & Carbón & $1-12266$ & $2050 \pm 80 \mathrm{BP}$ & $2230-1830$ & $280-120 \mathrm{cal}$ AD & Ibero-Romano republicano \\
\hline $8 \mathrm{a}$ & Carbón & $1-12718$ & $2920 \pm 100 \mathrm{BP}$ & $3370-2810$ & $1420-860$ & Bronce final \\
\hline $8 b$ & Carbón & $1-17919$ & $3270 \pm 150 \mathrm{BP}$ & $3860-3180$ & $1910-1230$ & Bronce inicial \\
\hline $8 \mathrm{c}$ & Carbón & UBAR-767 & $3430 \pm 110 \mathrm{BP}$ & $3980-3420$ & $2030-1470$ & Bronce inicial \\
\hline 9 & Carbón & $1-12717$ & $4080 \pm 100 \mathrm{BP}$ & $4920-4320$ & $2970-2370$ & Neolítico final-Calcolitico \\
\hline 9 & Carbón & $1-13315$ & $4130 \pm 110 \mathrm{BP}$ & $4930-4370$ & $2980-2420$ & Neolitico final-Calcolitico \\
\hline 9 & Carbón & $1-13313$ & $4160 \pm 160 \mathrm{BP}$ & $5100-4260$ & $3150-2310$ & Neolitico final-Calcolitico \\
\hline 9 & Hueso humano & $1-11533$ & $4225 \pm 90 \mathrm{BP}$ & $4980-4500$ & $3030-2550$ & Neolitico final-Calcolitico \\
\hline 9 & Carbón & UBAR-1074 & $4425 \pm 50 \mathrm{BP}$ & $5350-4790$ & $3400-2840$ & Neolitico final \\
\hline 10 & Semilla & OxA-15490 & $5279 \pm 31 \mathrm{BP}$ & $6220-5940$ & $4270-3990$ & Neolitico medio postcardial \\
\hline $10 \mathrm{~b}$ & Carbón & UBAR-1281 & $5075 \pm 40 \mathrm{BP}$ & $5950-5710$ & $4000-3760$ & Neolitico medio posteardial \\
\hline $10 \mathrm{~b}$ & Hueso humano & Beta-210652 & $5340 \pm 40 \mathrm{BP}$ & $6280-5960$ & $4330-4010$ & Neolitico medio postcardial \\
\hline $10 b$ & Hueso humano & UBAR-1282 & $5260 \pm 40 \mathrm{BP}$ & $6230-5870$ & $4280-3920$ & Neolitico medio posteardial \\
\hline 11 & Hueso humano & Beta 197134 & $5290 \pm 40 \mathrm{BP}$ & $6220-5940$ & $4270-3990$ & Neolitico post cardial \\
\hline 11 & Carbón & $1-17918$ & $5350 \pm 150 \mathrm{BP}$ & $6440-5800$ & $4490-3850$ & Neolitico postcardial \\
\hline 11 & Carbón & UBAR-1193 & $5370 \pm 45 \mathrm{BP}$ & $6340-5980$ & $4390-4030$ & Neolítico postcardial \\
\hline 11 & Hueso humano & Beta-363819 & $5460 \pm 40 \mathrm{BP}$ & $6340-6180$ & $4390-4230$ & Neolítico postcardial \\
\hline 11 & Carbón & I-13314 & $5470 \pm 110 \mathrm{BP}$ & $6500-5980$ & $4550-4030$ & Neolitico postcardial \\
\hline 11 & Carbón & UBAR 766 & $5470 \pm 140 \mathrm{BP}$ & $6560-5920$ & $4610-3970$ & Neolítico postcardial \\
\hline 11 & Hueso humano & OxA-29640 & $5487 \pm 33 \mathrm{BP}$ & $6360-6200$ & $4410-4250$ & Neolitico postcardial \\
\hline 11 & Hueso & Beta-363818 & $5540 \pm 40 \mathrm{BP}$ & $6430-6270$ & $4480-4320$ & Neolítico postcardial \\
\hline 11 & Carbón & UBAR-1310 & $5560 \pm 50 \mathrm{BP}$ & $6440-6280$ & $4490-4330$ & Neolitico post cardial \\
\hline 11 & Hueso humano & OxA-2964I & $5568 \pm 34 \mathrm{BP}$ & $6440-6280$ & $4490-4330$ & Neolítico post cardial \\
\hline 11 & Hueso & Beta-238657 & $5570 \pm 40 \mathrm{BP}$ & $6440-6280$ & $4490-4330$ & Neolitico post cardial \\
\hline 11 & Carbón & Beta-394625 & $5730 \pm 30 \mathrm{BP}$ & $6640-6440$ & $4690-4490$ & Neolítico postcardial \\
\hline $11 \mathrm{~b}$ & Carbón & $1-11789$ & $5700 \pm 110 \mathrm{BP}$ & $6750-6270$ & $4800-4320$ & Neolitico postcardial \\
\hline $11 \mathrm{~b}$ & Hueso & Beta-210653 & $5790 \pm 40 \mathrm{BP}$ & $6690-6490$ & $4740-4540$ & Neolitico post cardial \\
\hline $11 \mathrm{~b}$ & Carbón & $1-11787$ & $5800 \pm 160 \mathrm{BP}$ & $6990-6270$ & $5040-4320$ & Neolítico posteardial \\
\hline 14 & Carbón & Beta-179900 & $5980 \pm 40 \mathrm{BP}$ & $6940-6700$ & $4990-4750$ & Neolítico epicardial \\
\hline 17 & Carbón & Beta-127898 & $6050 \pm 110 \mathrm{BP}$ & $7240-6640$ & $5290-4690$ & Neolitico cardial final \\
\hline 18 & Semilla & OxA-15491 & $6375 \pm 34 \mathrm{BP}$ & $7430-7230$ & $5480-5280$ & Neolítico cardial \\
\hline 18 & Semilla & OxA-15489 & $6391 \pm 34 \mathrm{BP}$ & $7440-7240$ & $5490-5290$ & Neolitico cardial \\
\hline 18 & Semilla & UBAR 760 & $6405 \pm 50 \mathrm{BP}$ & $7470-7230$ & $5510-5310$ & Neolitico cardial \\
\hline 18 & Semilla & OxA-15488 & $6421 \pm 34 \mathrm{BP}$ & $7460-7260$ & $5520-5280$ & Neolítico cardial \\
\hline 20 & Carbón & Beta-230733 & $7320 \pm 50 \mathrm{BP}$ & $8240-8000$ & $6290-6050$ & Mesolitico \\
\hline 21 & Carbón & Beta-179899 & $9360 \pm 40 \mathrm{BP}$ & $10710-10470$ & $8760-8520$ & Epipaleolitico \\
\hline 21 & Hueso & Beta-230734 & $10540 \pm 60 \mathrm{BP}$ & $12770-12290$ & $10820-10340$ & Epipaleolítico \\
\hline
\end{tabular}

Tabla 1. Cova de Can Sadurní. Dataciones radiocarbónicas.

Table 1. Can Sadurní cave. Radiocarbon dates.

el perfil G-9/8 de color marrón claro (10YR 6/8) y con cierta carbonatación en la parte superior del techo. El contacto respecto al anterior es neto y con una geometría con tendencia tabular.

Correspondería a las capas 17 y 16 (Neolítico antiguo cardial final).

- Limos arcillosos con cantos y restos carbonosos y cenicientos. CS.X. Potencia media $32 \mathrm{~cm}$. El contacto con respecto a CS.XI es de continui- dad estratigráfica y su geometría con tendencia a tabular.

Se han distinguido cuatro subniveles:

CS.X.4. Potencia entre 5 y $10 \mathrm{~cm}$, aunque en el sector F-8 aumenta ligeramente de potencia. Está formado por una matriz de limos arcillosos con arenas de color pardo oscuro (10YR 4/2) con gran presencia de carbones. Arqueológicamente se atribuye a la capa 15. CS.X.3. Potencia entre 3 y $6 \mathrm{~cm}$. Compuesto de 
cantos y gravas de caliza de morfología subredondeada y subangulosa con limos arcillosos de color marrón (10YR 6/2). Corresponde a la capa 14. En el sector de J/F-9 aparecen bloques pero muy dispersos. El contacto con respecto a CS.X.4 es difuso.

CS.X.2. Potencia media $5 \mathrm{~cm}$. Aumenta considerablemente la matriz, también de limos arcillosos de color marrón (10YR 5/2) con gran abundancia de restos carbonosos. Se atribuye a la capa 13.

La atribución cultural es de Neolítico antiguo epicardial.

CS.X.1. Área de redil. Se localiza en el sector G$\mathrm{H} / 8$ y $\mathrm{G}-\mathrm{H} / 7$ y se atribuye a la capa 12 . Esta área tiene, por el momento, una longitud de aproximadamente $150 \mathrm{~cm}$ (Fig. 5e) y una potencia entre 6 y $3 \mathrm{~cm}$ en el sector G-H/7. La secuencia es la siguiente de muro a techo (Bergadà and Cervelló, 2011):

CS.X.1b. Potencia entre 1 y $3,5 \mathrm{~cm}$. Formada por limos de color marrón oscuro (10YR 3/2) con alguna grava y una gran cantidad de residuos orgánicos de origen vegetal y excremental parcialmente carbonizados. Presenta cierta cicatriz erosiva con respecto a CS.X.2.

CS.X.1a. Potencia entre 1,5 y $6 \mathrm{~cm}$. Compuesta por una acumulación carbonatada blanquecinagrisácea (10YR 6/2) junto a carbones y algunas partículas arenosas. Geometría tabular.

Arqueológicamente corresponde a una fase epicardial o poscardial muy incipiente.

- Bloques con limos arcillosos. CS.IX. La potencia media entre 17 y $20 \mathrm{~cm}$. En general domina la fracción de bloques y cantos de morfología subangulosa, aunque en los sectores J-7/F-8 aumentan considerablemente de tamaño. Cabe señalar que este aumento se acentúa en dirección a la entrada de la cueva. La matriz es de limos arcillosos con alguna fracción arenosa, de color marrón (5YR 5/2). El contacto es erosivo con respecto a CS.X en algunos sectores y con pendiente norte aunque no tan pronunciada como el nivel CS.XII. Corresponde a la capa 11b (Neolítico postcardial inicial).

- Limos arcillosos y cantos con restos carbonosos y cenicientos. CS.VIII. Potencia media 72 $\mathrm{cm}$. Está formado por limos arcillosos con arenas de color marrón oscuro (5YR 6/1) con cantos dispersos. Aparece gran cantidad de restos carbonosos entre la matriz. La geometría es tabular y el contacto neto con respecto a CS.IX. Se atribuye a la capa 11.

También se han localizado áreas de redil prácti- camente en la base del nivel, concretamente en el perfil G-H/7. Por el momento no podemos definir su extensión ya que se delimitó en el perfil. La potencia es de $3 \mathrm{~cm}$ y la secuencia de muro a techo es:

CS.VIII. b. Potencia $1,5 \mathrm{~cm}$. Compuesta de limos de color marrón oscuro (5YR 2.5/2) con restos parcialmente carbonizados y muy alterados por la actividad biológica.

CS.VIII. a. Potencia $1,5 \mathrm{~cm}$. Formada por una acumulación carbonatada de color blanco grisáceo (5YR 6/1) con algún residuo carbonoso.

A partir de este nivel en el sector de los cuadros 10/11 de la cuadrícula de la excavación hay una cierta pendiente norte en contacto con la pared de la cueva; lo cual, hace que haya una acumulación más acentuada de cantos y de algún bloque de calibre pequeño. Corresponde al Neolítico postcardial inicial.

- Cantos y bloques con limos arcillosos. CS.VII. Potencia media $10 \mathrm{~cm}$. Formado por cantos de 1 a $6 \mathrm{~cm}$ de morfología subangulosa con algunas fisuras y algunos de ellos con carbonataciones. En el sector J-I-H-G/9-10 aparecen numerosos bloques de morfología angulosa de calibre mediano. La matriz es de limos arcillosos con arenas de color pardo 7,5YR 5/2.

Se acentúan los cantos y bloques en el sector en contacto con la pared de la cavidad (cuadrícula 10/11). Su contacto, en general, es neto y con una geometría tabular; aunque en algunos sectores es erosiva con respecto a CS.VIII. Se correlaciona con la capa $10 \mathrm{~b}$ y correspondería al Neolítico medio postcardial.

- Limos arenosos con arcillas y algún canto. CS.VI. Potencia media $13 \mathrm{~cm}$. Matriz limoarenosa con arcillas de color marrón (5YR 4/2). Su contacto es difuso con respecto a CS.VII especialmente en el perfil F-8. Es la capa 10 (Neolítico medio postcardial).

- Limos arenosos con cantos y algún bloque. CS.V. Potencia $45 \mathrm{~cm}$. Formado por dos subniveles

CS.V.2. Potencia entre 7 y $13 \mathrm{~cm}$. Compuesto por cantos de morfología subredondeada y bloques de un calibre entre 14 y $20 \mathrm{~cm}$ con tendencia a subangular. Aparecen con algunas fisuras y con trazas de óxidos e hidróxidos de hierro. La matriz es de limos arenosos con arcillas de color pardo (7,5YR 5/2). Su geometría es de muro erosivo. Se atribuye a la capa $9 b$.

CS.V.1. Potencia $32 \mathrm{~cm}$. Domina la fracción fina de limos arenosos de color marrón oscuro (7,5YR 4/2) con algún canto y bloque. Hay una 
gran cantidad de carbones. Su geometría tiene tendencia a ser tabular y el contacto con el nivel anterior es difuso. Se asigna a la capa 9.

La atribución cultural de ambos subniveles es de Neolítico final/Calcolítico.

- Limos arcillosos con cantos y bloques. CS.IV. Potencia media $25 \mathrm{~cm}$. Se subdivide en dos subniveles:

CS.IV.2. Potencia media $13 \mathrm{~cm}$ aunque en el sector del cuadro D-6 puede llegar a $40 \mathrm{~cm}$ por los bloques. Está formado por cantos subangulosos con una cierta clasificación y bloques con una matriz de limos arcillosos de color marrón oscuro 5YR 4/2. Tiene un buzamiento hacia el norte. Hacia el sector D/8-9, los cantos y bloques van perdiendo su representación con un dominio de la matriz. Su geometría es de muro erosivo con respecto a CS.V. Corresponde a la capa $8 b$ y c (Bronce inicial).

CS.IV.1. Potencia media $12 \mathrm{~cm}$. Compuesta por limos arcillosos de color marrón oscuro 5YR 4/1 con algún canto muy disperso. Capa 8 a (Bronce final).

- Limos arenosos con cantos. CS.III. Potencia media $30 \mathrm{~cm}$. Compuesto por limos arenosos de color marrón oscuro (5YR 4/2) con cantos de alrededor de los $10 \mathrm{~cm}$. En la parte inferior aparecen cantos que según los investigadores responderían quizás a una fase de nivelación antrópica. Arqueológicamente se le atribuye a las capas 7 y 6 (época Ibero-Romana).

- Cantos con limos arcillosos. CS.II. Potencia media $13 \mathrm{~cm}$. Está formado por cantos de morfología subredondeada y subangulosa con limos arcillosos de color marrón 5YR 3/2. Corresponde a la capa 5 (época Romana alto imperial).

- Limos arcillosos. CS.I. Potencia media $12 \mathrm{~cm}$. Compuesto por limos arcillosos de color pardo (5YR 4/1) con cantos con ligeras trazas de disgregación. Según los investigadores en este nivel había intrusiones de época reciente. Capa 4 (época Romana bajo imperial).

- Costra carbonatada discontinua. CS.0. Potencia media $10 \mathrm{~cm}$. Es una costra carbonatada que aparece de forma muy discontinua y fragmentada. Su formación es reciente. Se atribuye a la capa 3.

\section{Análisis micromorfológico}

A la hora de realizar el estudio microestratigráfico de los niveles identificados hemos creído conveniente utilizar el término de microfacies (abreviado en el texto $\mathrm{mf} / \mathrm{mfs}$ ) tal como fue concebido originalmente para designar los cambios litológicos, orgánicos y de origen antrópico localizados en lámina delgada (Courty, 2001; Dabrio and Hernando, 2003). De acuerdo con Goldberg et al., (2009), somos de la opinión que es imprescindible establecer una relación sistemática entre los aspectos o caracteres documentados en lámina delgada y los establecidos en el campo y viceversa, así como a un nivel regional aunque en registros kársticos sea más difícil de establecer.

A continuación presentamos las microfacies que se han distinguido relacionadas con los niveles identificados en el campo. En las tablas que adjuntamos (Tablas 2, 3, 4, 5, 6 y 7) aparecen las descripciones micromorfológicas de las mismas. Hemos creído interesante referenciar las distintas tablas con la secuencia cronocultural que presenta el yacimiento. De todas formas aunque hemos intentado realizar un muestreo sistemático de todo el registro; algunos de los niveles o subniveles no se han podido muestrear por tener un gran contenido de cantos y bloques como son: CS.X.3, CS. IX, CS.VII, CS.V.2, CS.IV.2 y CS.II.

Se han documentado en toda la secuencia un total de 26 microfacies (Tabla 8), que las hemos agrupado en los siguientes grupos para sintetizar los resultados:

- Limos arcillosos con cantos con microestructura vesicular

- Limos arcillosos con arenas y cantos con agregados de origen excremental

- Limos arcillosos con trazas de óxidos e hidróxidos de $\mathrm{Fe}$ e inclusiones fosfatadas

- Acumulaciones excrementales y vegetales mineralizados y carbonizados

- Capas de fitolitos y excrementos organofosfatados con aportes detríticos

- Limos arenosos con cantos y agregados excrementales removilizados

- Limos arenosos con movilización y acumulación de arcillas

- Limos arcillosos con nódulos criptocristalinos fosfatados

La fracción litológica y mineralógica está formada principalmente por: caliza micrítica, cuarzo, feldespatos, plagioclasa y calcita.

a) Limos arcillosos con cantos con microestructura vesicular

Se incluyen las microfacies siguientes: 26 y 25 (CS.XIV), 24 y 23 (CS. XIII) y 4 (CS.IV.1) (Tablas 2 y 7$)$.

La formación de las mfs. 26, 25, 24 y 23 sería de tipo solifluidal en el cual las gravas y cantos 
Bergadà, M.M., et al., 2018. Procesos deposicionales y antrópicos en el registro... Boletín Geológico y Minero, 129 (1/2): $251-284$

\begin{tabular}{|c|c|c|}
\hline Niveles & Perfiles & Micromorfología \\
\hline Estratigráficos & Número de muestra & Microfacies \\
\hline \multirow[b]{2}{*}{ CS. XIII } & $\begin{array}{l}\text { G-8 / F-8 } \\
\text { (M.19) }\end{array}$ & $\begin{array}{l}\text { Mf. 23. Cantos y limos arcillosos con arenas } \\
\text { Microestructura: granular. Porosidad: } 25 \% \text { (huecos de empaquetamiento compuesto). Masa } \\
\text { basal g/f } 50 \mu \mathrm{m} 3 / 1 \text {. Cantos y gravas de caliza de morfología subangulosa/subredondeada con } \\
\text { algunas fisuras. Algunos en disposición inclinada o vertical. La fracción fina de limos arcillosos } \\
\text { con arenas. Distribución relacionada: porfírica. Fábrica de birrefringencia cristalítica y calcítica. } \\
\text { Carbones con estructura vegetal leñosa de } 250 \mu \mathrm{m}-1 \mathrm{~mm}\left({ }^{* *}\right) \text {; huesos de } 250 \mu \mathrm{m} \text { a } 2 \mathrm{~mm}\left({ }^{* *}\right) \\
\text { amarillo en LPP. Rasgos edáficos: revestimientos }(++) \text { de material fino con dominios orientados } \\
\text { en agregados o huecos y rasgos de disolución }(++) \text { en el material calizo. }\end{array}$ \\
\hline & $\begin{array}{l}\text { G-8 / F-8 } \\
\text { (M.19 y M.20) }\end{array}$ & $\begin{array}{l}\text { Mf. 24. Limos arcillosos con arenas } \\
\text { Microestructura: bloques subangular (separación mediana entre agregados)/vesicular/granular. } \\
\text { Porosidad: } 20 \% \text { fisuras, vesículas y huecos de empaquetamiento. Masa basal g/f } 50 \mu \mathrm{m} 1 / 2 \text {. } \\
\text { Limos arcillosos con arenas. Distribución relacionada: porfírica. Fábrica de birrefringencia cris- } \\
\text { talítica y calcítica. Carbones de } 25 \mu \mathrm{m} \text { a } 2 \mathrm{~mm} \text { con estructura vegetal de morfología tabular (**); } \\
\text { huesos }\left({ }^{* * *}\right) \text { de } 250 \mu \mathrm{m} \text { a } 2 \mathrm{~mm} \text { amarillo en LPP, algunos en disposición vertical. Rasgos edá- } \\
\text { ficos: nódulos órticos de óxidos e hidróxidos de Fe repartidos por la masa basal (+), revesti- } \\
\text { mientos (++) de material fino con dominios orientados en agregados o huecos y rasgos de diso- } \\
\text { lución }(++) \text { en el material calizo. }\end{array}$ \\
\hline CS. XIV & $\begin{array}{l}\text { G-8 / F-8 } \\
\text { (M.21 y M.22) }\end{array}$ & $\begin{array}{l}\text { Mf. 26. Limos arcillosos con gravas } \\
\text { Microestructura: bloques subangulares (separación mediana entre agregados), vesicular y gra- } \\
\text { nular. Porosidad: } 20 \% \text { (fisuras, vesículas y huecos de empaquetamiento compuesto). Masa } \\
\text { basal g/f } 50 \mu \mathrm{m} 1 / 2 \text {. Limos arcillosos con arenas fina con gravas y cantos. Distribución relacio- } \\
\text { nada: porfírica. Fábrica de birrefringencia cristalítica y calcítica. Carbones ( } 1 \mathrm{~mm}-2 \mathrm{~mm} \text { ) con } \\
\text { estructura leñosa }\left(*^{* *}\right) \text { y huesos }>2 \mathrm{~mm}\left({ }^{* * *}\right) \text { mayoritariamente de color amarillo y con fisu- } \\
\text { ras en LPP; aunque alguno blanquecino con trazas de combustión. Rasgos edáficos: revesti- } \\
\text { mientos }(+++++) \text { de material fino }(>1 \mathrm{~mm} \text { de grosor) en huecos con dominios orientados, diso- } \\
\text { lución en huesos y en material calizo con hipo-revestimientos criptocristalinos de color amarillo } \\
(+++++) \text { y nódulos órticos de óxidos e hidróxidos de Fe }(++) \text { y actividad biológica - agregados y } \\
\text { cámaras- }(++) \text {. }\end{array}$ \\
\hline \multicolumn{3}{|c|}{$\begin{array}{l}\text { Clasificación de abundancia de edaforrasgos (Bullock et al., 1985):+ raro }(<2 \%) ;++ \text { ocasional }(2-5 \%) ;+++ \text { muchos }(5-10 \%) ;++++ \text { abun- } \\
\text { dante }(10-20 \%) ;++++ \text { muy abundante }(>20 \%) \text {. }\end{array}$} \\
\hline
\end{tabular}

Tabla 2. Descripción del análisis micromorfológico de los niveles CS.XIV y CS.XIII (secuencia epipaleolítica y mesolítica).

Table 2. Description of the micromorphological analysis of the CS.XIV and CS.XIII levels (Mesolithic and Epipaleolithic sequence).

aparecen con cierta orientación y en la mf. 4 sería un aporte heterométrico de tipo coluvional. En algunas mfs. 26, 25 y 4 tienen una microestructura vesicular (Fig. 7a) y la mf. 23 de tipo granular.

Los huecos vesiculares son muy comunes en contextos con matrices limoarcillosas y en condiciones de saturación de agua en que se retiene el aire del suelo. Esta licuefacción puede ser originada por el deshielo (Bertran and Coutard, 2004; Van Vliet-Lanoë, 2010) o por un episodio importante de lluvias que origina un movimien- to de masa (Bertran and Texier, 1999; Karkanas and Goldberg, 2013).

Como rasgos edáficos, destacaríamos las trazas de iluviación de arcillas en suspensión, localizadas principalmente en las paredes de los huecos de la matriz (Fig. 7b). Este proceso también es común en este tipo de depósitos e indicaría presencia de agua y condiciones no floculantes (suelos descarbonatados), propias de medios húmedos y percolantes. Como consecuencia de este ambiente se observan procesos de disolución en el material calizo (Fig. 7c), 
Bergadà, M.M., et al., 2018. Procesos deposicionales y antrópicos en el registro... Boletín Geológico y Minero, 129 (1/2): 251-284

\begin{tabular}{|c|c|c|}
\hline Niveles & Perfiles & Micromorfología \\
\hline Estratigráficos & Número de muestra & Microfacies \\
\hline & & $\begin{array}{l}\text { Mf. 20. Limos arenosos } \\
\text { Microestructura: masiva/bloques subangulares. Porosidad: } 5 \% \text { (cavitarios, huecos de empa- } \\
\text { quetamiento compuesto). Masa basal c/f } 50 \mu \mathrm{m} 1 / 4 \text {. Limos arcillosos con arenas finas. } \\
\text { Distribución relacionada: porfírica. Fábrica de birrefringencia indiferenciada. Aparecen reparti- } \\
\text { das por la masa basal esferolitas de calcio }\left(*^{* * *}\right) \text { y algún fitolito de sílice }\left({ }^{*}\right) \text {; así como, algún } \\
\text { hueso }(*) \text {, carbón }\left({ }^{*}\right) \text { y elemento cerámico }\left({ }^{*}\right) \text {. Rasgos edáficos: nódulos órticos de óxidos e } \\
\text { hidróxidos de Fe }(++++) \text { e hipo-revestimientos calcíticos }(++) \text { de } 250 \mu \mathrm{m} \text { de grosor en huecos. }\end{array}$ \\
\hline CS. XI & $\begin{array}{l}\text { G-9/G-8 } \\
\text { (M.17) }\end{array}$ & 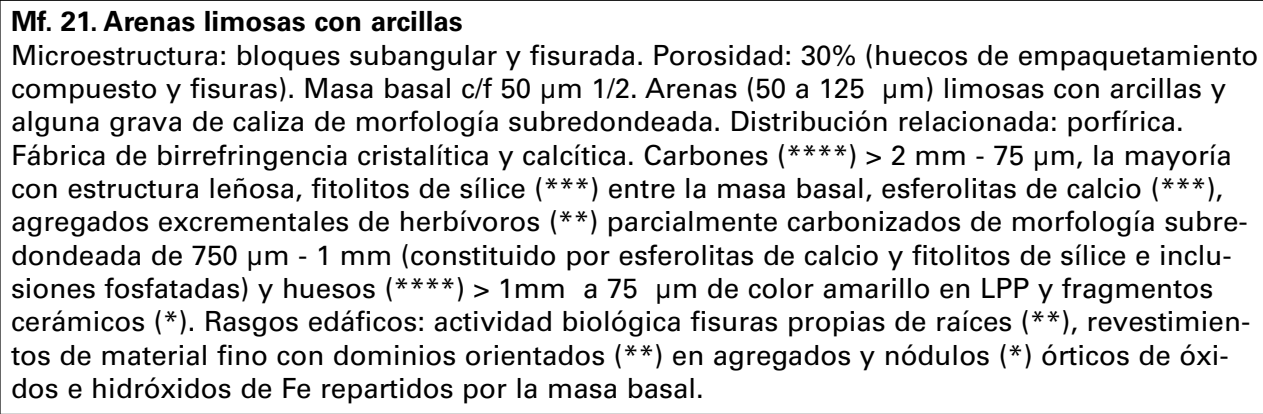 \\
\hline CS. XII. & $\begin{array}{l}\text { G-8/F-8 } \\
\text { (M.18) }\end{array}$ & $\begin{array}{l}\text { Mf. 22. Limos arcillosos con arenas y cantos y gravas } \\
\text { Microestructura: granular/de bloques subangular (separación fina/mediana entre agregados). } \\
\text { Porosidad: } 25 \% \text { (huecos de empaquetamiento compuesto y complejo, fisuras). Masa basal g/f } \\
50 \mu \mathrm{m} 3 / 1 \text {. Cantos y gravas de morfología subredondeada y limos arcillosos. Distribución rela- } \\
\text { cionada: porfírica/quitónica. Fábrica de birrefringencia cristalítica y calcítica. Carbones }\left(*^{* *}\right) \text { de } \\
250 \mu \mathrm{m} \text { a } 2 \mathrm{~mm} \text { con estructura vegetal leñosa y no leñosa, esferolitas de calcio dispersas }\left(^{* *}\right) \text {, } \\
\text { fitolitos de sílice }\left({ }^{* *}\right) \text { de formas rectangulares y ovales impregnadas con soluciones fosfata- } \\
\text { das, pseudomorfos calcíticos de drusas }\left({ }^{* *}\right) ; \text { huesos }\left({ }^{*}\right) \text { de } 200 \mu \mathrm{m} \text { a }>2 \mathrm{~mm} \text { amarillos y en } \\
\text { ocasiones anaranjados y pseudo carbonizados en LPP y algún resto malacológico }\left({ }^{*}\right)>1 \mathrm{~mm} \text {. } \\
\text { Agregados excrementales de herbívoro }\left({ }^{* *}\right) \text { de morfología subredondeada con esferolitas de } \\
\text { calcio y fitolitos de sílice alargados entrelazados, humificados de } 500 \mu \text { a } 1 \mathrm{~mm} \text {. Fragmento } \\
\text { cerámico de morfología subredondeada y fragmento de sílex de }>1 \mathrm{~mm} \text {. Rasgos edáficos: } \\
\text { revestimientos de material fino con cierta birrefringencia en agregados }(+) \text { y trazas de óxidos } \\
\text { e hidróxidos de Fe en la matriz y nódulos órticos de } 250 \mu \mathrm{m} \text { y en los cantos }(+) \text {. }\end{array}$ \\
\hline
\end{tabular}

Tabla 3. Descripción del análisis micromorfológico de los niveles CS.XII y CS.XI (Neolítico antiguo cardial y final).

Table 3. Description of the micromorphological analysis of the CS.XII and CS.XI levels (Cardial Early Neolithic and Late).

en residuos cenicientos (Fig. 7d) y en los huesos que conlleva a la formación de hipo-revestimientos de fosfato (apatito) en el material detrítico (Figs. 7e y 7f), típico de lugares ricos en fosfato en este caso procedente de los huesos y que reaccionan con el material calizo, produciéndose un reemplazamiento de la calcita por el apatito (Karkanas and Goldberg, 2010). Tal como se desprende del microanálisis efectuado en uno de los hipo-revestimientos localizados en la mf. 26.

Se documenta una interrupción en la sedimentación entre la mf. 25 y la mf. 24 por la actividad biológica.
En las mfs. 24 y 23 hay un cierto cambio con respecto a las microfacies anteriores. Una tendencia a un dominio de la microestructura de tipo granular, como también un cambio de orientación (vertical o inclinada) de huesos, carbones y de algunos de los cantos de morfología subangulosa y ligeramente fisurados indicadores de procesos de hielo-deshielo moderados que originarían procesos de crioturbación (Van Vliet-Lanoë, 2010).

b) Limos arcillosos con arenas y cantos con agregados de origen excremental Están representadas las microfacies 22 (CS.XII), 21 y 20 (CS.XI) (Tabla 3). Su origen es detrítico 

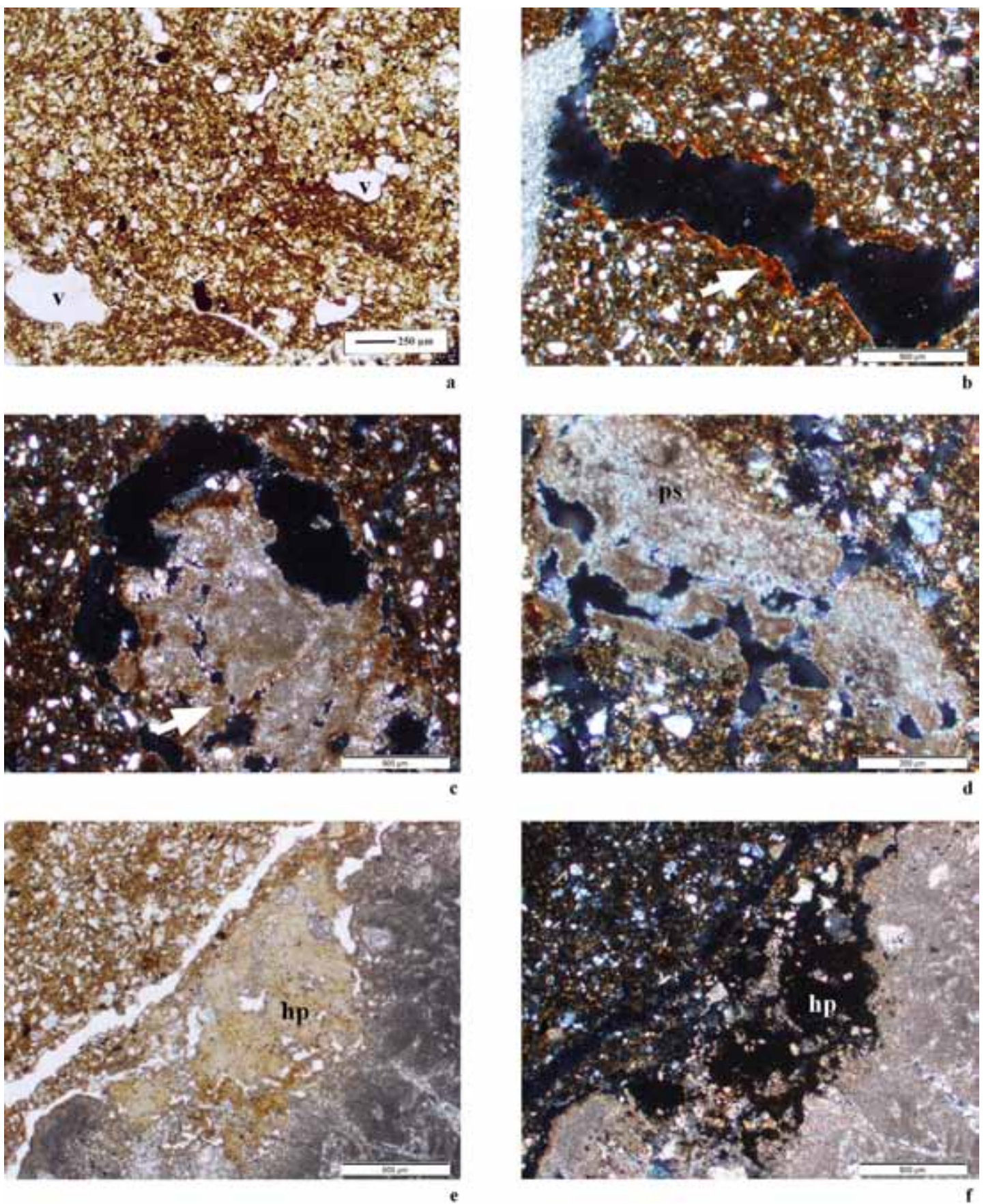

Figura 7. Rasgos micromorfológicos de CS.XIV (Epipaleolítico), CS.XIII (Mesolítico) y CS.V.1 (Bronce final).

a. Mf. 25. Microestructura vesicular. Huecos vesiculares (v). LPP.

b. Mf.26. Hipo-revestimiento de material fino con dominios orientados (flecha) en un hueco. LPX .

c. Mf.26. Trazas de disolución muy acentuada en el material detrítico calizo (flecha). LPX.

d. Mf.4. Detalle de un pseudomorfo (ps) calcítico de origen vegetal con porosidad elevada. LPX.

e. Mf.26. Hipo-revestimiento (hp) criptocristalino amarillo en un canto de caliza. LPP.

f. Mf. 26. La misma imagen (e) en LPX.

Figure 7. Micromorphological features: CS.XIV (Epipaleolithic), CS.XIII (Mesolithic) and CS. V.1 (Late Bronze).

a. Mf.25. Vesicular microstructure. Vesicles voids (v). PPL.

b. Mf.26. Oriented domains (arrow) of fine material hypocoating in a void. XPL.

c. Mf.26. Traces of dissolution in detrital limestone material (arrow). XPL.

d. Mf.4. Detail of a calcite pseudomorph (ps) of a plant with high porosity. XPL.

e. Mf.26. Yellow cryptocrystalline hypocoating (hp) in the limestone gravel. PPL.

f. Mf.26. Same as (e). XPL. 
Bergadà, M.M., et al., 2018. Procesos deposicionales y antrópicos en el registro... Boletín Geológico y Minero, 129 (1/2): $251-284$

\begin{tabular}{|c|c|c|}
\hline Niveles & Perfiles & Micromorfología \\
\hline Estratigráficos & Número de muestra & Microfacies \\
\hline CS. X.2 & $\begin{array}{l}\text { F-G/8 } \\
\text { (M.13) } \\
\text { G-9/G-8 } \\
\text { (M.16) }\end{array}$ & $\begin{array}{l}\text { Mf. 18. Limos arcillosos con trazas de óxidos e hidróxidos de Fe e inclusiones fosfatadas } \\
\text { Microestructura: bloques subangulares. Porosidad: } 25 \% \text { (huecos de empaquetamiento com- } \\
\text { puesto y fisuras). Masa basal c/f } 50 \mu \mathrm{m} 1 / 2 \text {. Limos arcillosos. Distribución relacionada: porfí- } \\
\text { rica. Fábrica de birrefringencia cristalítica y calcítica. Carbones }\left(*^{* * *}\right)>2 \mathrm{~mm}-75 \mu \mathrm{m} \text {, la } \\
\text { mayoría con estructura leñosa, fitolitos de sílice de formas alargadas }\left({ }^{* *}\right) \text { entre la masa basal, } \\
\text { esferolitas de calcio }(*) \text {, agregados excrementales de herbívoros }\left({ }^{*}\right) \text { parcialmente carboniza- } \\
\text { dos de morfología subredondeada de } 750 \mu \mathrm{m}-1 \mathrm{~mm}(\text { constituido por esferolitas de calcio y } \\
\text { fitolitos de sílice, pseudomorfos calcíticos de drusas e inclusiones fosfatadas) y huesos }\left({ }^{*}\right)> \\
1 \mathrm{~mm} \text { a } 75 \mu \mathrm{m} \text { de color amarillo en LPP, fragmentos cerámicos }\left({ }^{*}\right) \text {. Rasgos edáficos: actividad } \\
\text { biológica fisuras propias de raíces }(+) \text { y nódulos }(++++) \text { órticos de óxidos e hidróxidos de Fe } \\
\text { repartidos por la masa basal; inclusiones fosfatadas }(++) \text { en forma de abanico con formación } \\
\text { de vivianita. }\end{array}$ \\
\hline CS. X.4 & $\begin{array}{l}\text { G-9/G-8 } \\
\text { (M.16) }\end{array}$ & $\begin{array}{l}\text { Mf. 19. Limos arcillosos con restos carbonosos y cenicientos con óxidos e hidróxidos de Fe } \\
\text { Microestructura: bloques subangulares/masiva. Porosidad: } 15 \% \text { (huecos de empaquetamien- } \\
\text { to compuesto y fisuras). Masa basal g/f } 50 \mu \mathrm{m} 1 / 2 \text {. Limos arcillosos con arenas } 75 \text { a } 125 \mu \mathrm{m} \text { - } \\
\text { Distribución relacionada: porfírica. Fábrica de birrefringencia cristalítica y calcítica. Carbones } \\
\text { de } 1 \mathrm{~mm} \text { a }>2 \mathrm{~mm} \text { con estructura vegetal leñosa }(* * *) \text {; algunos restos vegetales parcialmente } \\
\text { carbonizados, fragmentos cenicientos con estructura celular }\left({ }^{*}\right) \text { de } 1 \text { a } 1,5 \mathrm{~mm} \text {, esferolitas de } \\
\text { calcio dispersas }\left(*^{*}\right) \text {, fitolitos de sílice de formas alargadas con inclusiones fosfatadas }\left(^{* *}\right) \text {, } \\
\text { pseudomorfos calcíticos de drusas }(* *) ; \text { huesos }(*) \text { de } 750 \mu \mathrm{m} \text { a } 1 \mathrm{~mm} \text { de color amarillo en } \\
\text { LPP. Agregados excrementales fosfatados con bordes de óxidos e hidróxidos de Fe de } 1 \mathrm{~mm} \\
\left({ }^{*}\right) \text {, fragmento de cáscara de huevo de ave }\left({ }^{*}\right) \text { con ligeras trazas de combustión de } 600 \mu \mathrm{m} \text {. } \text {. } \\
\text { Fragmento de sílex }\left(*^{*}\right) \text { de }>1 \mathrm{~mm} \text {. Rasgos edáficos: revestimientos de material fino con } \\
\text { dominios orientados en agregados }(+) \text { y trazas de óxidos e hidróxidos de Fe en la matriz en } \\
\text { nódulos órticos de } 250 \mu \mathrm{m} \text { y en revest/hipo-revestimientos en los cantos, carbones, excre- } \\
\text { mentos }(++) \text {. }\end{array}$ \\
\hline \multicolumn{3}{|c|}{$\begin{array}{l}\text { Clasificación de frecuencias (Bullock et al., } 1985):{ }^{*} \text { muy poco }(<5 \%) ;{ }^{*} \text { poco }(5-15 \%) ;{ }^{* *} \text { presente }(15-30 \%) ;{ }^{* * *} \text { frecuente }(30-50 \%) ; \\
* * * * \text { dominante }(50-70 \%) ; * * * * * \text { muy dominante }(>70 \%) .\end{array}$} \\
\hline
\end{tabular}

Tabla 4. Descripción del análisis micromorfológico del nivel CS.X (Neolítico antiguo epicardial).

Table 4. Description of the micromorphological analysis of the CS.X level (Epicardial Early Neolithic).

de tipo coluvional y por la actividad antrópica. Se caracterizan por aportes heterométricos ricos en grava y de escasa cohesión interna, principalmente en la mf. 22, e incorpora abundantes agregados granulares junto a restos óseos, malacológicos, cerámicos, etc. En la mf. 21 el flujo disminuye notablemente; pero, especialmente en la mf. 20 que llega a decantarse el material fino.

Este grupo de microfacies destaca, desde el punto de vista antrópico, por la presencia en la masa basal de esferolitas de calcio, que en este caso son fecales (Brochier, 1996; Canti, 1997), que en LPP se distinguen por ser mineralizaciones esféricas formadas por cristalizaciones de carbonato cálcico y en LPX se identifican por su extinción en cruz. Así como, por la aparición de algunos excrementos muy posiblemente de ovicaprinos caracterizados por presentar una morfología subredondeada con esferolitas de calcio fecales junto a fitolitos de sílice entrela- zados e inclusiones fosfatadas con material detrítico (Bergadà, 1998; Polo Díaz, 2010), ligeramente quemados junto a acumulaciones fosfatadas.

También aparecen los pseudomorfos calcíticos de drusas, indicadores de cenizas, que pueden presentar morfologías variadas más o menos esféricas y constituidas por una serie de cristales de extremos angulosos y con una disposición radial (Polo Díaz, 2010). Según Brochier (1996) se localizan de forma más habitual en hojas de materiales leñosos. Además, aparecen fitolitos de sílice de variadas morfologías. Todos esos componentes -fitolitos, esferolitas de calcio y drusas- que aparecen dispersos entre la masa basal son propios de la composición de coprolitos (Polo Díaz, 2010). Su presencia nos permite a considerar la existencia de un área de estabulación de animales, más intensa en las mfs. 21 y 20, pero removida por los aportes coluvionales. 
Bergadà, M.M., et al., 2018. Procesos deposicionales y antrópicos en el registro... Boletín Geológico y Minero, 129 (1/2): $251-284$

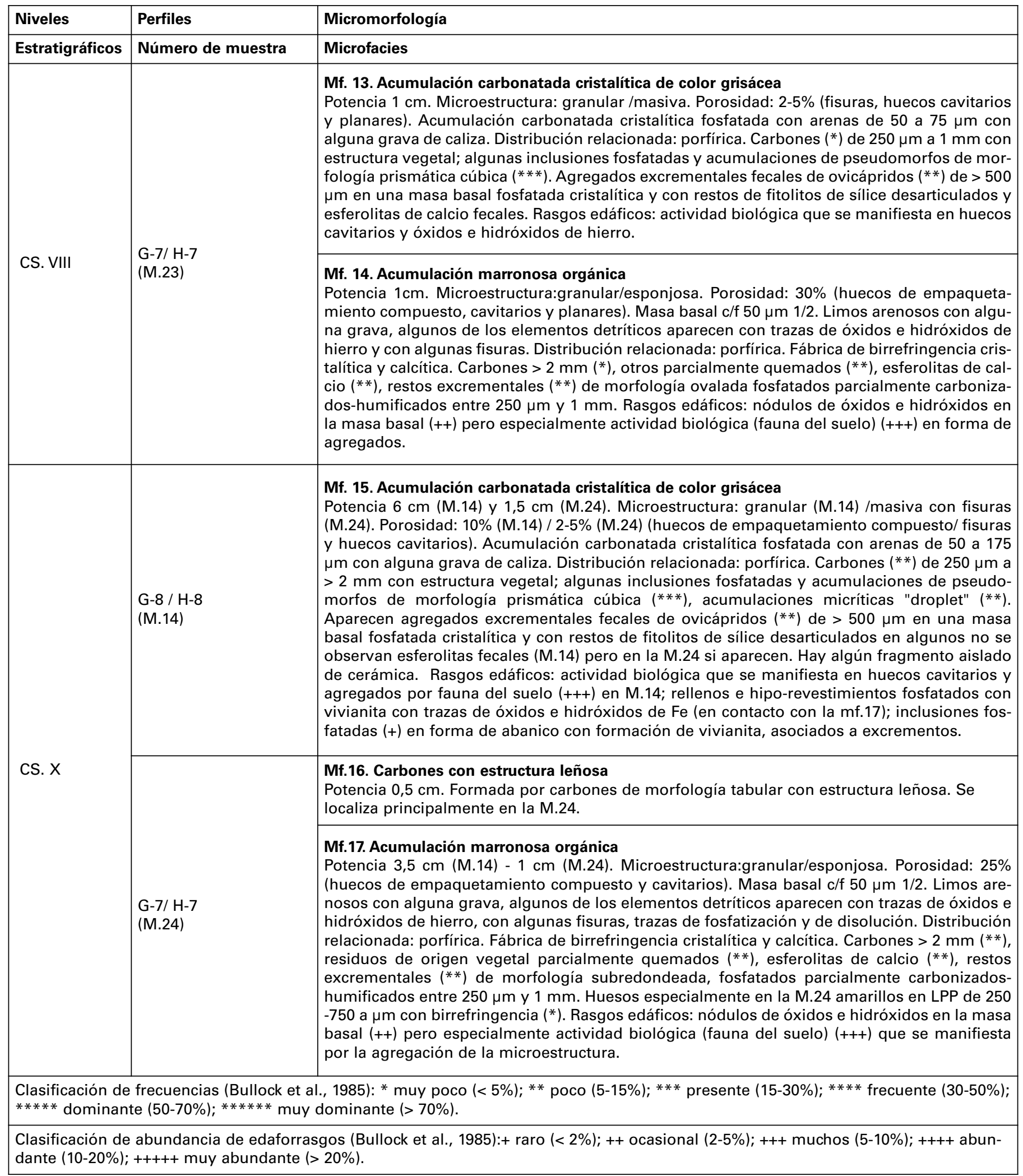

Tabla 5. Descripción del análisis micromorfológico de las áreas de rediles con trazas de combustión de CS.X y CS.VIII (Neolítico antiguo epicardial y postcardial inicial).

Table 5. Description of the micromorphological analysis of the stabling areas with traces of combustion of the CS.X and CS.VIII (Early Postcardial and Epicardial Early Neolithic). 
Bergadà, M.M., et al., 2018. Procesos deposicionales y antrópicos en el registro... Boletín Geológico y Minero, 129 (1/2): $251-284$

\begin{tabular}{|c|c|c|}
\hline Niveles & Perfiles & Micromorfología \\
\hline Estratigráficos & Número de muestra & Microfacies \\
\hline CS. VI & G-8 / F-8 (M.6-M.5) & 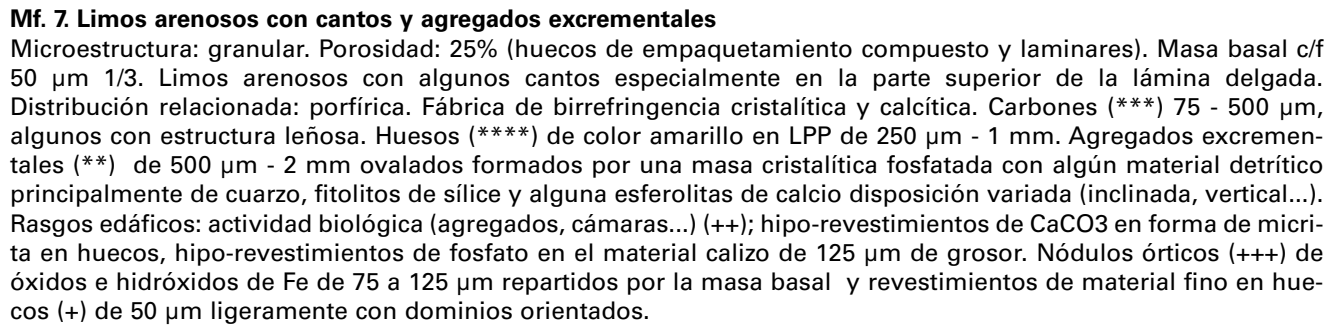 \\
\hline \multirow{3}{*}{ CS. VIII } & $\begin{array}{l}\text { G-8 / F-8 (M.7-M.6) } \\
\text { F-9 (M.28 - inhuma- } \\
\text { ción 1) G-11 (M.29 - } \\
\text { inhumación 2) } \\
\end{array}$ & $\begin{array}{l}\text { Mf.8. Limos arcillosos con fragmentos de capas de fitolitos de sílice y agregados excrementales. } \\
\text { Con las mismas características que la Mf.9 con un aumento de la fracción detrítica y con fragmentación de las lami- } \\
\text { naciones. }\end{array}$ \\
\hline & $\begin{array}{l}\text { G-8 / F-8 M.8/M.7/ } \\
\text { E-6 M.27 }\end{array}$ & $\begin{array}{l}\text { Mf. 10. Limos arenosos con agregados excrementales fosfatados } \\
\text { Potencia } 10 \mathrm{~cm} \text {. Microestructura: granular/laminar. Porosidad } 10-20 \% \text { (cavitarios, huecos de empaquetamiento } \\
\text { compuesto). Masa basal c/f } 50 \mu \mathrm{m} 1 / 3 \text {. Limos arcillosos con arenas finas. Distribución relacionada: porfírica. Fábrica } \\
\text { de birrefringencia cristalítica y calcítica. Fragmentos de costras sedimentarias. Carbones }\left({ }^{*}\right) \text { de } 250 \mu \mathrm{m} \text { a } 2 \mathrm{~mm} \text { con } \\
\text { estructura vegetal, impregnaciones organofosfatadas entre la masa basal, agregados excrementales }\left(^{* *}\right) \text { de } 500 \\
\mu \mathrm{m}-1 \mathrm{~mm} \text { ovalados-circulares con una masa basal organofosfatada con fitolitos desarticulados con esferolitas de } \\
\text { calcio, aunque en algunos no aparecen y partículas de cuarzo, resto ovalado }\left({ }^{*}\right) \text { de } 200 \mu \mathrm{m} \text { con estructura celular } \\
\text { vegetal que podría corresponder a semilla. Rasgos edáficos: revestimientos de material fino (arcillas) (+), nódulos } \\
\text { órticos de óxidos e hidróxidos de Fe }(+) \text { y actividad biológica (cámaras, agregados, algunas fisuraciones de raíces) } \\
(++) \text {. }\end{array}$ \\
\hline & $\begin{array}{l}\text { G-8 / F-8 } \\
\text { (M.13-M.10) }\end{array}$ & 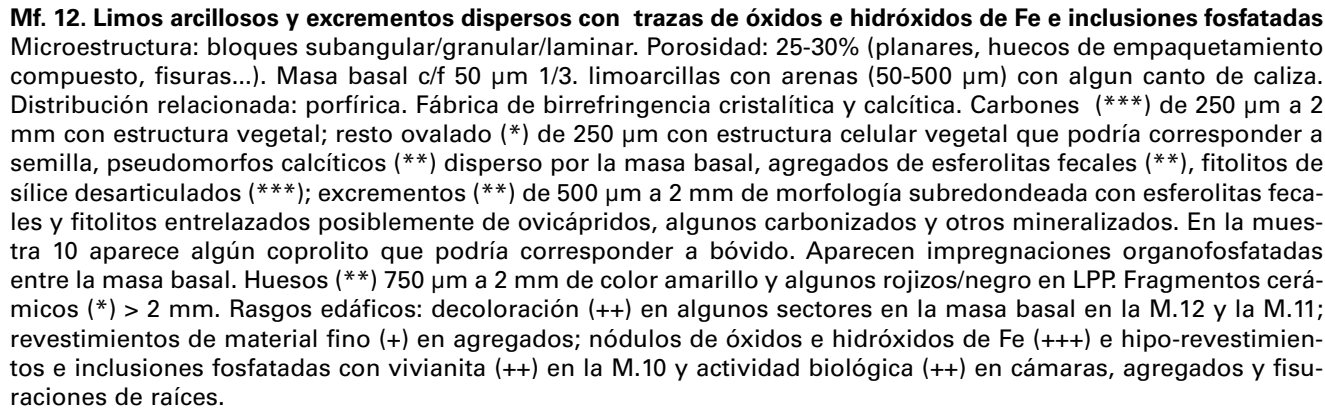 \\
\hline
\end{tabular}

Clasificación de frecuencias (Bullock et al., 1985): * muy poco $(<5 \%) ; * *$ poco $(5-15 \%) ; * * *$ presente $(15-30 \%) ; * * *$ frecuente $(30-50 \%) ; * * * *$ dominante $(50-70 \%) ; * * * * *$ muy dominante $(>70 \%)$.

Clasificación de abundancia de edaforrasgos (Bullock et al., 1985):+ raro $(<2 \%)$;++ ocasional $(2-5 \%) ;+++$ muchos $(5-10 \%)$; ++++ abundante $(10-20 \%)$; +++++ muy abundante (> 20\%).

Tabla 6. Descripción del análisis micromorfológico de las áreas de rediles sin trazas de combustión de CS.VIII (Neolítico postcardial inicial) y del nivel CS. VI (Neolítico medio postcardial).

Table 6. Description of the micromorphological analysis of the stabling areas without traces of combustion of the CS. VIII (Early Postcardial Neolithic) and CS. VI level (Postcardial Middle Neolithic). 
Bergadà, M.M., et al., 2018. Procesos deposicionales y antrópicos en el registro... Boletín Geológico y Minero, 129 (1/2): $251-284$

\begin{tabular}{|c|c|c|}
\hline Niveles & Perfiles & Micromorfología \\
\hline Estratigráficos & Número de muestra & Microfacies \\
\hline CS. I. & D-7/8. M.1 & $\begin{array}{l}\text { Mf. 1. Limos arcillosos con nódulos criptocristalinos fosfatados } \\
\text { Microestructura: granular/fisural y localmente laminar. Porosidad: } 15 \% \text { (huecos de empaque- } \\
\text { tamiento compuesto, cavitarios y algunos planares). Masa basal c/f } 50 \mu \mathrm{m} 1 / 2 \text {. Limos arcillo- } \\
\text { sos, algunas de las gravas aparecen con fisuras y opacidad. Distribución relacionada: porfíri- } \\
\text { ca. Fábrica de birrefringencia cristalítica y calcítica. Carbones }\left({ }^{* *}\right) \text { de } 75 \mu \mathrm{m} \text { a tamaño } \\
\text { centimétrico. Huesos }\left({ }^{*}\right) \text { de } 150 \mu \mathrm{m} \text { a } 1 \mathrm{~mm} \text { de color amarillo, anaranjado y ligeramente } \\
\text { negro en LPP, nódulos de apatito criptocristalinos amarillos }\left(^{* *}\right) \text { entre la masa basal de } 75- \\
150 \mu \mathrm{m} \text { y ceràmica }\left({ }^{*}\right) \text { Rasgos edáficos: nódulos órticos }(++) \text { de óxidos e hidróxidos de Fe y } \\
\text { actividad biológica }(+++) \text { (agregados de origen excremental por la fauna del suelo). }\end{array}$ \\
\hline \multirow{2}{*}{ CS. III } & \multirow{2}{*}{ D-7/8. M.2 } & $\begin{array}{l}\text { Mf. 2. Limos arenosos } \\
\text { Microestructura:granular/bloques subangulares. Porosidad: } 30-40 \% \text { (huecos de empaqueta- } \\
\text { miento compuesto y fisuras). Masa basal c/f } 50 \mu \mathrm{m} 1 / 2 \text { limos arenosos con cantos. } \\
\text { Distribución relacionada: porfírica. Fábrica de birrefringencia cristalítica y calcítica. Carbones } \\
\left(*^{*}\right) \text { de } 50-550 \mu \mathrm{m} \text {, huesos }\left(^{*}\right) 250 \mu \mathrm{m} \text { a } 1,5 \mathrm{~mm} \text { de color amarillo pálido en LPP y ceràmi- } \\
\text { ca }\left(*^{* *}\right)>2 \mathrm{~mm} \text {. Rasgos edáficos: nódulos órticos de óxidos e hidróxidos de Fe repartidos } \\
\text { por la masa basal. }\end{array}$ \\
\hline & & $\begin{array}{l}\text { Mf. 3. Limos arenosos con arcillas } \\
\text { Microestructura: granular/fisural. Porosidad: } 15 \% \text { (huecos de empaquetamiento compuesto y } \\
\text { cavitarios). Masa basal c/f } 50 \mu \mathrm{m} 1 / 2 . \text { limos arenosos y arcillas con cantos algunos en posición } \\
\text { vertical o inclinada. Distribución relacionada: porfírica. Fábrica de birrefringencia cristalítica y } \\
\text { calcítica. Carbones }\left(^{*}\right) \text { de } 50-600 \mu \mathrm{m} \text {, huesos }\left(^{* *}\right) \text { de } 300 \mu \mathrm{m} \text { a } 2 \mathrm{~mm} \text { de color amarillo y ana- } \\
\text { ranjado en LPP y ceràmica }>1 \mathrm{~mm} \quad\left(^{*}\right) \text {. Rasgos edáficos: nódulos órticos de óxidos e hidró- } \\
\text { xidos de Fe. }\end{array}$ \\
\hline CS. IV.1 & D-8. M.3 & $\begin{array}{l}\text { Mf. 4. Limos arcillosos con huecos vesiculares } \\
\text { Microestructura: granular/vesicular Porosidad: } 20 \% \text { (huecos de empaquetamiento compues- } \\
\text { to, vesículas y cavitarios) Masa basal c/f } 50 \mu \mathrm{m} 1 / 2 \text {. Limos arcillosos con arenas finas y algún } \\
\text { canto. Distribución relacionada: porfírica. Fábrica de birrefringencia cristalítica y calcítica. } \\
\text { Carbones }\left({ }^{*}\right) 50-75 \mu \mathrm{m} \text {, relicto celular calcítico de origen vegetal }\left({ }^{*}\right) \text { de } 1 \mathrm{~mm} \text { en proceso de } \\
\text { disolución, huesos }\left({ }^{*}\right) 500 \mu \mathrm{m} \text { a }>2 \mathrm{~mm} \text { de color amarillo en LPP, nódulos de fosfatos cris- } \\
\text { talíticos }\left({ }^{*}\right) \text { y algún fragmento de cerámica }\left({ }^{*}\right) \text {. Rasgos edáficos: hipo-revestimientos de fos- } \\
\text { fato en el material calizo }(+) \text {, disolución en el material calizo }(+++) \text { y revestimientos de mate- } \\
\text { rial fino en dominios orientados y en forma de inclusiones }(+++) \text {. }\end{array}$ \\
\hline CS. V.1 & $\begin{array}{l}\text { G-8 / F-8 } \\
\text { (M.4) }\end{array}$ & $\begin{array}{l}\text { Mf. 6. Limos arenosos con arcillas } \\
\text { Microestructura: bloques subangulares/granular. Porosidad: } 25-30 \% \text { (fisuras y huecos de } \\
\text { empaquetamiento compuesto). Masa basal c/f } 50 \mu \mathrm{m} 1 / 3 \text {. Limos arenosos con arcillas con } \\
\text { algún canto de caliza que presenta rasgos de disolución y de fosfatización. Distribución rela- } \\
\text { cionada: porfírica. Fábrica de birrefringencia cristalítica y calcítica. Carbones }\left(^{* *} \text { ) de } 50 \mu \mathrm{m} \text { a }\right. \\
2 \mathrm{~mm} \text {, restos malacológicos }\left(^{*}\right) 1-2 \mathrm{~mm} \text {. Rasgos edáficos: porosidad en el material calizo } \\
\text { (disolución) (+), nódulos órticos de óxidos e hidróxidos de Fe }(+) \text {, revestimientos y rellenos en } \\
\text { huecos de material fino de } 50 \mu \mathrm{m} \text { con dominios orientados }(++) \text {. }\end{array}$ \\
\hline \multicolumn{3}{|c|}{$\begin{array}{l}\text { Clasificación de frecuencias (Bullock et al., } 1985) \text { : }{ }^{*} \text { muy poco }(<5 \%) ; * * \text { poco }(5-15 \%) ; * * * \text { presente }(15-30 \%) ;{ }^{* * *} \text { frecuente }(30-50 \%) \text {; } \\
* * * * \text { dominante }(50-70 \%) ;{ }^{* * * * *} \text { muy dominante }(>70 \%) \text {. }\end{array}$} \\
\hline
\end{tabular}

Tabla 7. Descripción del análisis micromorfológico de los niveles CS. V (Neolítico final/Calcolítico), CS.IV (Bronce final), CS.III (IberoRomano) y CS.I (Bajo Imperio Romano).

Table 7. Description of the micromorphological analysis of the CS. V. (Late Neolithic/Chalcolithic), CS.IV (Late Bronze), CS.III (Ibero-Roman Epoch) and CS.I (Late Roman Empire) levels. 

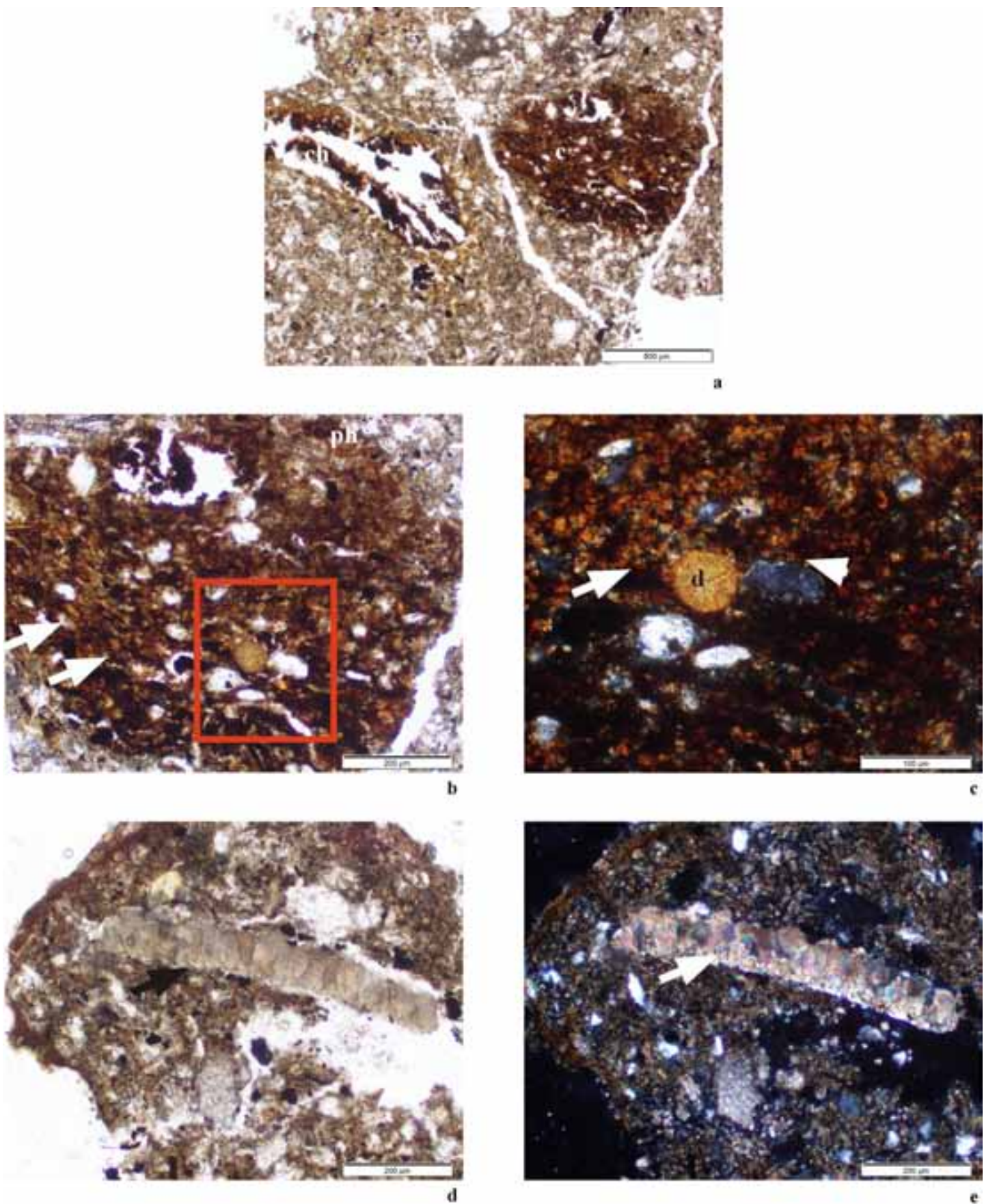

Figura 8. Rasgos micromorfológicos de CS.X (Neolítico antiguo epicardial).

a. Mf.18. Vista general de un fragmento de carbón (ch) y de un coprolito (c) de ovicáprido. LPP.

b. Mf.18. Detalle del coprolito con fitolitos de sílice (ph) y nódulos fosfatados (flecha). LPP.

c. Mf.18. Imagen del recuadro en rojo. Nótese la acumulación de esferolitas de calcio (flecha) y detalle de drusas -d- (agregado de cristales de oxalato cálcico). LPX.

d. Mf.19. Fragmento de cáscara de huevo de ave (flecha). LPP.

e. Mf.19. La misma imagen (d) en LPX. Obsérvese los cristales columnares. LPX.

Figure 8. Micromorphological features of the CS.X (Epicardial Early Neolithic).

a. Mf.18. Overview of a charcoal fragment (ch) and an ovicaprine coprolite (c). PPL.

b. Mf.18. Detail of coprolite with silica phytoliths (ph) and phosphatic nodules (arrow). PPL.

c. Mf.18. Image in red box. Note the accumulation of calcium spherulites (arrow) and detail of druse (aggregates of calcium oxalate crystals) (d). XPL.

d. Mf. 19. Bird's eggshell fragment (arrow). PPL.

e. Mf.19. Same as (d) in XPL. Note the columnar crystals (arrow). 
Bergadà, M.M., et al., 2018. Procesos deposicionales y antrópicos en el registro... Boletín Geológico y Minero, 129 (1/2): $251-284$

\begin{tabular}{|c|c|c|c|c|}
\hline Nivel & Microfacies & Procesos edafosedimentarios y antrópicos & Capas & Secuencia arqueológica \\
\hline IV.1 & 4 & coluvión & $8 a$ & Bronce final \\
\hline VI & 7 & coluvión & 10 & Neolítico medio postcardial \\
\hline \multirow{3}{*}{ VIII } & $\begin{array}{c}8 \\
9 \\
10 \\
11\end{array}$ & $\begin{array}{l}\text { Redil (ovicaprinos y bóvidos) sin combustión } \\
\text { con eventuales arroyadas y trazas de pisoteo }\end{array}$ & \multirow{3}{*}{11} & \multirow{3}{*}{ Neolítico postcardial } \\
\hline & 12 & $\begin{array}{l}\text { Hidromorfismo y formación vivianita } \\
\text { Coluvión (-), actividad pastoril }(+)\end{array}$ & & \\
\hline & $\begin{array}{l}13 \\
14\end{array}$ & \multirow{2}{*}{$\begin{array}{l}\text { Redil (ovicaprinos) con combustión } \\
\text { Hidromorfismo y formación vivianita }\end{array}$} & & \\
\hline \multirow{2}{*}{$X$} & $\begin{array}{l}15 \\
16 \\
17\end{array}$ & & 12 & Epicardial/postcardial? \\
\hline & $\begin{array}{l}18 \\
19\end{array}$ & $\begin{array}{l}\text { Hidromorfismo } \\
\text { Coluvión (-), actividad pastoril (+) }\end{array}$ & 13,15 & Neolítico epicardial \\
\hline XIV & $\begin{array}{l}25 \\
26\end{array}$ & Solifluxión & 21 & Epipaleolítico \\
\hline
\end{tabular}

Tabla 8. Síntesis de la secuencia microestratigráfica de la Cova de Can Sadurní (ámbito estudiado).

Table 8. Synthesis of the microstratigraphic sequence of the Can Sadurní cave (studied area).

También aparecen otros componentes propios de la actividad humana (cerámica, sílex, huesos...) con distintas trazas de combustión (Antolín et al., 2011).

En cuanto a los procesos edáficos, se generaliza la microestructura de bloques subangulares casi en toda la secuencia del registro indicadora de procesos de humectación y desecación de la matriz (Fitzpatrick, 1990). La localización de masas amorfas fosfatadas pueden ser resultado de la alteración de los restos excrementales (mf. 20); también, la actividad biológica, especialmente raíces, en la mf. 21 en huecos, rasgo que nos da a entender la exposición en superficie de dicha microfacies en algunos episodios; así cómo, en la mf. 20 donde aparecen hiporevestimientos calcíticos en bioporos de raíces como resultado de la rápida precipitación del carbonato cálcico debido al metabolismo de la raíz (Durand et al., 2010). Se detecta un inicio de procesos hidromórficos (niveles de agua fluctuante) con el aumento de la presencia de 
nódulos, en los cuales las condiciones oxidantes dominaban.

c) Limos arcillosos con trazas de óxidos e hidróxidos de $\mathrm{Fe}$ e inclusiones fosfatadas

Este grupo está representado por las microfacies 19 (CS.X.4) y 18 (CS.X.2) (Tabla 4) y por la microfacies 12 de CS.VIII (Tabla 6).
La sedimentación se debe a aportaciones de tipo coluvional de débil energía y una mayor actividad antrópica de tipo pastoril: fitolitos de sílice de morfologías alargadas, excrementos con gran contenido de fosfato, coprolitos parcialmente carbonizados de ovicaprinos (Figs. $8 \mathrm{a}, 8 \mathrm{~b}$ y $8 \mathrm{c})$ y residuos cenicientos con estruc-
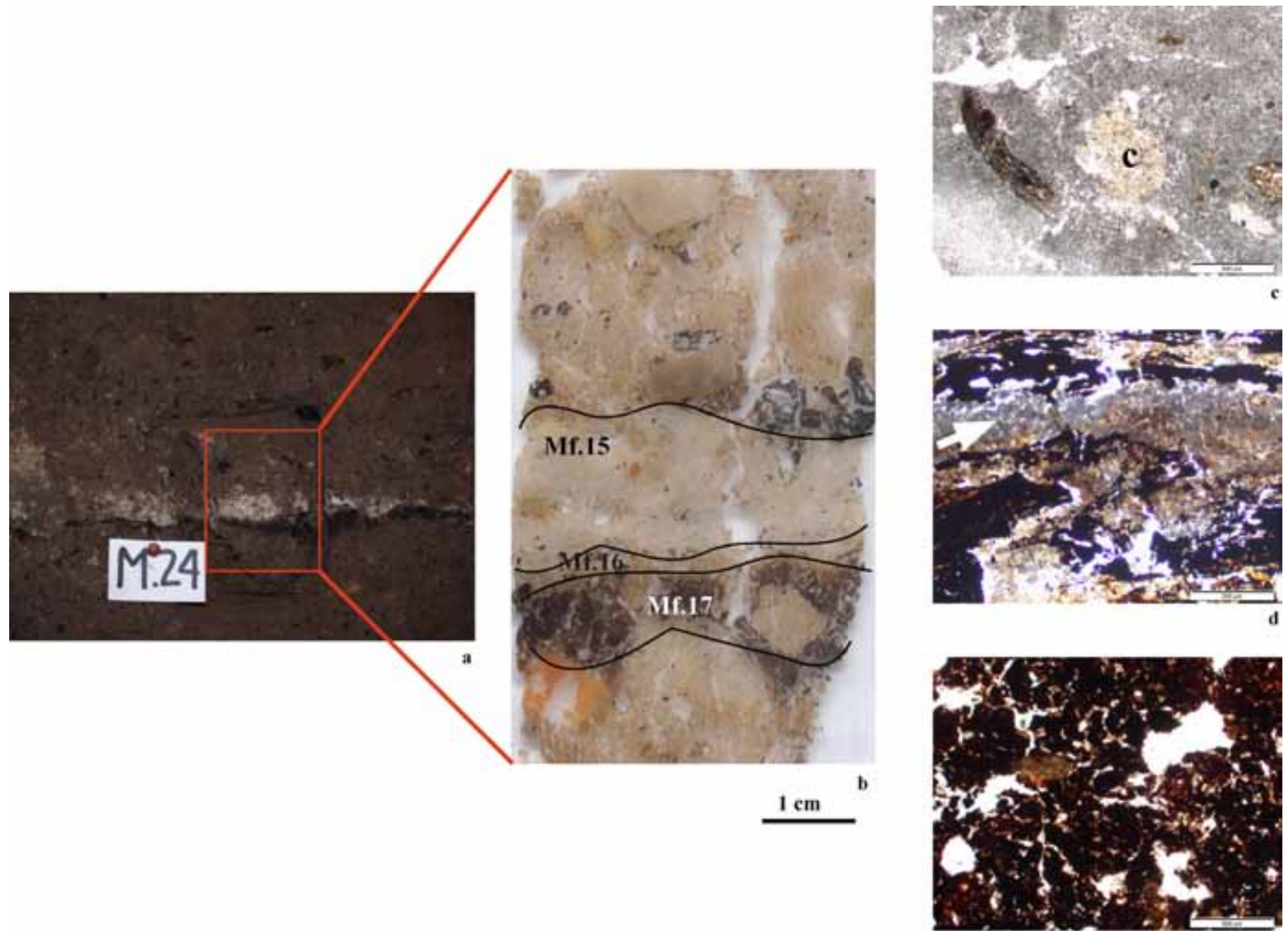

Figura 9. Área de rediles. CS.X (Neolítico antiguo epicardial).

a. Zona del muestreo de la M.24 en el sector G-7/H-7. Se distingue la capa blanquecina i la capa marronosa.

b. Lámina delgada. Se distinguen las tres microfacies: mf. 15, mf.16 y mf.17.

c. Mf.15. Acumulación de ceniza compuesto por pseudomorfos calcíticos de origen vegetal. Se observa algún resto carbonoso y un coprolito de ovicáprido (c) mineralizado por la combustión. LPP.

d. Mf.16. Acumulación carbonosa de restos leñosos junto a pseudomorfos calcíticos cúbicos (flecha). LPP.

e. Mf.17. Vista de excremento carbonizado. LPP.

Figure 9. Stabling area. CS.X (Epicardial Early Neolithic).

a. Sampling area M.24 in the G-7/H-7 Sector. The white layer and the brownish layer are distinguished.

b. Thin section. Three microfacies are distinguished: $\mathrm{mf} .15, \mathrm{mf} .16$ and $\mathrm{mf} .17$.

c. Mf.15. Ash accumulation composed of calcite pseudomorphs of plant origin. A charcoal fragment and ovicaprine mineralizad coprolite

(c) is observed. PPL.

d. Mf.16. Charcoal accumulation of woody debris with cubic calcite pseudomorphs (arrow). PPL.

e. Mf.17. Charred dung PPL. 
tura celular. El aporte coluvional es mucho más débil que las microfacies anteriormente tratadas; lo cual conlleva a que la conservación de los restos sea mejor, rasgo que se denota muy especialmente en los agregados excrementales.

Los componentes propios de la actividad pastoril están removilizados por los aportes coluvionales y por la actividad de pisoteo que se observa en algunos sectores de la mf. 12 que se manifiesta por: una compactación de la masa basal, baja porosidad y la presencia de huecos planares (Mentzer, 2014; Miller et al., 2008).

EI hecho de localizar entre la masa basal restos de cáscara de huevo de ave (Figs. $8 \mathrm{~d}$ y $8 \mathrm{e}$ ) que se caracterizan por presentar cristales columnares de calcita dispuestos más o menos en ángulo recto (Durand et al., 2010), plantea la idea de que hubo fases de abandono en la cavidad que habrían sido aprovechadas por las aves para nidificar tal cómo se registra en la mf. 19.

Un aspecto interesante a destacar son los rasgos edáficos hidromórficos relacionados con la presencia abundante de óxidos e hidróxidos de $\mathrm{Fe}$, que nos sugieren un deficiente drenaje llegando a la presencia de vivianita $\left(\mathrm{Fe}_{3}\right.$ $\left.\left(\mathrm{PO}_{4}\right)_{2} .8 \mathrm{H}_{2} \mathrm{O}\right)$ en la mf. 18. Para su formación se requiere unas condiciones reductoras $y$ con una disponibilidad abundante de hierro y de fósforo. Se identifica fácilmente en base a su color azul y su pleocroísmo en LPP (McGowan and Prangnell, 2006; Karkanas and Goldberg, 2010). En nuestro caso su génesis es resultado por la abundancia de residuos ricos en fosfato (excrementos y materia vegetal) en un contexto reductor. Existen varios ejemplos de su aparición en contextos similares como los descritos por Milek (2012) y Nicosia (2008).

Estas condiciones reductoras también se constatan por las áreas decoloradas (grisáceas) observadas en algunos sectores de la mf. 12 (M.11) de CS.VIII debido a la movilización del Fe y la menor presencia de Mn (Dorronsoro et al., 2015).

d) Acumulaciones excrementales y vegetales mineralizados y carbonizados

Se incluyen las microfacies siguientes: 17, 16, 15 (CS.X); 14 y 13 (CS.VIII) (Tabla 5).

De base a techo se localizan tres tipos de microfacies:

- Acumulación orgánica de color marrón (mf. 14 y mf. 17) con una potencia de 1 a $3,5 \mathrm{~cm}$. Constituida principalmente por fragmentos excrementales con algún carbón y por acumu- laciones amarillas fosfatadas amorfas (Figs. 9a, $9 b$ y $9 e)$.

- Restos de carbones de estructura leñosa (mf. 16) con una potencia de $0,5 \mathrm{~cm}$ (Figs. $9 \mathrm{~b}$ y $9 \mathrm{~d}$ ).

- Acumulación carbonatada y cristalítica de color grisáceo de origen vegetal y algún agregado excremental (mf. $15 \mathrm{y} \mathrm{mf}$. 13) con una potencia media entre 1 a $6 \mathrm{~cm}$ (Figs. 9a, 9b y 9c).

Estas microfacies se localizan in situ por la disposición de sus componentes y están relacionadas a un proceso de quema, aspecto que incidiremos en el apartado de discusión.

Las microfacies oscuras responden mayoritariamente a restos excrementales que quedaron en superficie de ahí que haya mucha actividad biológica y luego posteriormente se produciría la quema a temperatura baja y en condiciones húmedas (Polo Díaz, 2010), rasgo confirmado por la neoformación de fosfatos como la vivianita (Figs. 10a y 10b). En cambio, las microfacies carbonatadas grisáceas -cenizas- son de origen vegetal y entre los componentes se localizan: pseudomorfos calcíticos (drusas y prismáticos) (Canti, 2003) y residuos micríticos redondeados denominados droplets (Courty et al., 1989; Polo Díaz, 2010). Los pseudomorfos de tipo prismático corresponden al igual que las drusas a restos de vegetales leñosos; aunque los prismas se hallan en la corteza y las drusas en las hojas (Brochier, 1996; Polo Díaz, 2010). Los residuos micríticos droplets son resultado de una combustión muy elevada de los restos vegetales. Otro indicador de la temperatura elevada que han sufrido estas microfacies se observa en las esferolitas de calcio de los excrementos, en algunas se carboniza el revestimiento orgánico que recubre a las esferolitas ennegreciendo su superficie (Brochier, 1996; Polo Díaz, 2010) y cuando han alcanzado temperaturas superiores a $600{ }^{\circ} \mathrm{C}$ ya están ausentes en los coprolitos (Bergadà, 1998).

Estas acumulaciones estarían formadas prácticamente por vegetales leñosos en las cuales la combustión sería a una temperatura más elevada y en un ambiente más aireado; el hecho que se localice la mf. 16 de carbones leñosos correspondería al mismo episodio pero con menos ventilación.

e) Capas de fitolitos y excrementos organofosfatados con aportes detríticos

Se localiza en las microfacies 11, 10, 9 y 8 de CS.VIII (Tabla 6). Corresponde a un episodio de estabulación muy posiblemente de ganado $y$ 

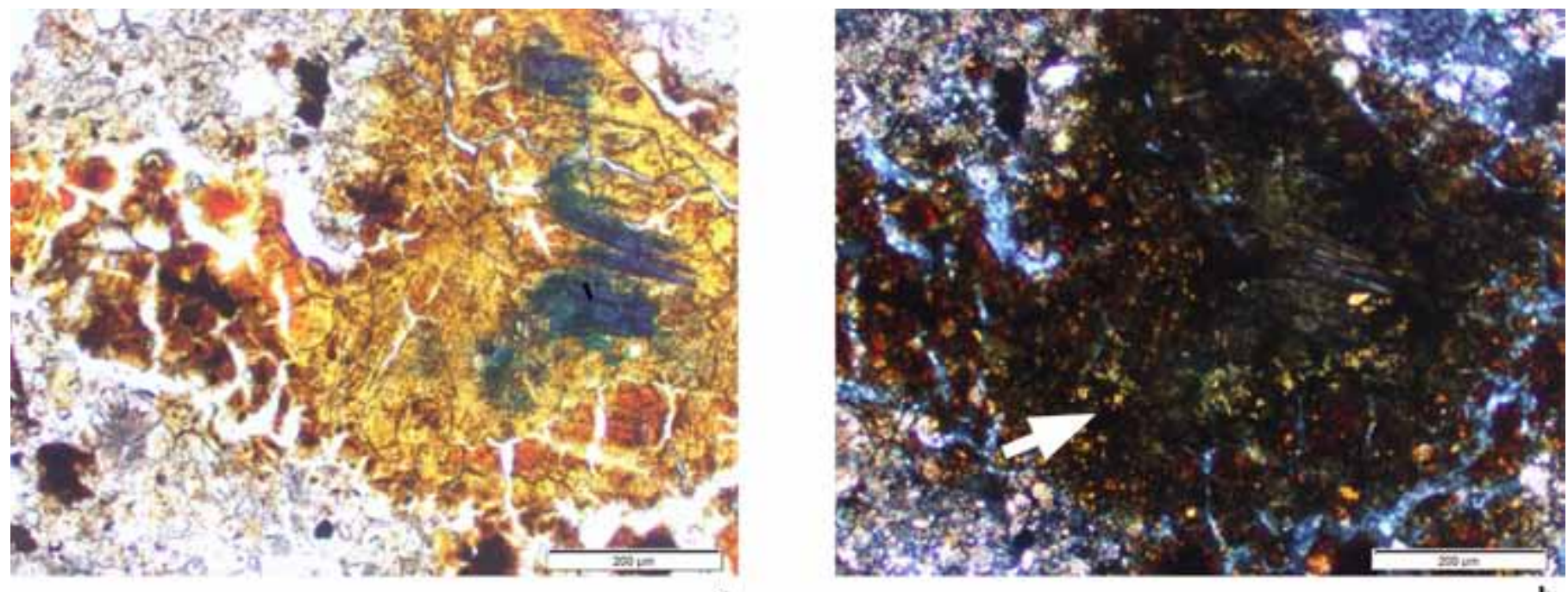

Figura 10. Área de rediles. CS.X (Neolítico antiguo epicardial).

a. Contacto entre la mf.17 y la mf.15. Acumulación fosfatada en un agregado excremental con la presencia de vivianita (v). LPP.

b. La misma imagen (a) en LPX. Nótese la presencia de esferolitas fecales (flecha). LPX.

Figure 10. Stabling area. CS.X (Epicardial Early Neolithic).

a. Contact between mf.17 and mf.15. Phosphatic accumulations in excremental aggregate with the occurrence of vivianite ( v). PPL.

b. Same as (a) in XPL. Note the presence of faecal spherulites (arrow). XPL.

de ovicaprinos. Se caracterizan por la presencia de capas compuestas por fitolitos de sílice (Fig. 11a), en ocasiones articulados y en otras desarticulados de morfologías variadas en una disposición horizontal o subhorizontal en especial en las mfs. 11 y 9 con una masa basal fina organofosfatada. También, se identifican algunos restos excrementales formados por fitolitos con cierta articulación laminar con una microestructura esponjosa y con poca presencia de elementos detríticos que podrían corresponder a bóvidos (Bergadà, 1998) (Figs. 11b y 11c), junto a otros de ovicaprino.

La mayoría de las microfacies están alteradas o bien por la introducción de aportes detríticos, arroyadas de débil energía como las mfs. 10 y 8 , que originan costras sedimentarias o bien por la actividad de pisoteo, mf. 11 y buena parte de la mf. 9 y también por la actividad de la fauna del suelo registrada en algunos sectores en casi todas las microfacies que es la causa de la microestructura de tipo granular. Quisiéramos puntualizar que en este complejo de microfacies aparece bien desarrollada la microestructura laminar, la cual en ocasiones es resultado de un proceso detrítico concretamente de costras sedimentarias, en que los huecos aparecen en sentido horizontal muy bien acomodados y sin continuidad en sentido vertical (Fig. 11d) (Bergadà, 1998; Pagliai and Stoops, 2010) muy bien localizada en la muestra 27. También, por pisoteo tal cómo hemos mencionado anteriormente acompañado por una fracturación in situ. Una de las microfacies donde se documenta una buena preservación de las capas es la mf. 9, y nos sugiere que la ocupación está in situ. Algunas de estas capas laminadas aparecen tan compactadas que resulta difícil de discernir si proceden de una acumulación vegetal, excremental o una combinación de ambas (Figs. 11e y 11f); problemática también localizada por Milek (2012).

Uno de los aspectos interesantes a destacar es la poca presencia o en ocasiones ausencia de esferolitas fecales tanto en las capas como en el interior de los excrementos a diferencia de las otras microfacies analizadas en este mismo yacimiento. La hipótesis que nos planteamos es que quizás los animales estabulados no hubieran producido en cantidad esferolitas; o bien, y a nuestro parecer más probable, es que en un medio altamente orgánico por la acumulación de restos excrementales y vegetales podría ocasionar la disolución de las esferolitas fecales calcíticas (Macphail et al., 2004; Milek, 2012). Este proceso podría darse ya que la descomposición de materia orgánica por bacterias y hongos va acompañada de liberación de áci- 

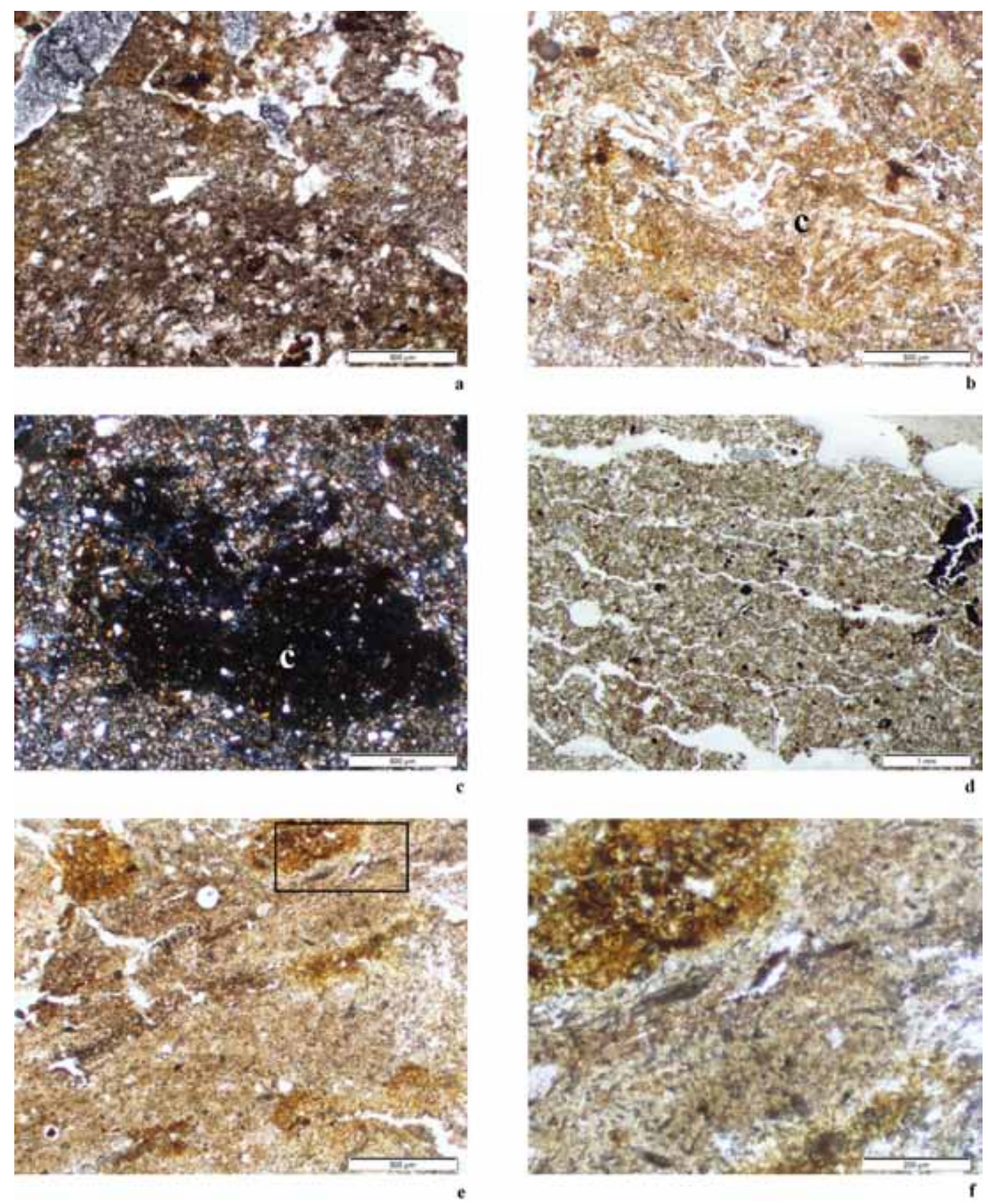

Figura 11. Área de rediles. CS.VIII. (Neolítico postcardial inicial).

a. Mf.9. Capa de fitolitos de sílice desarticulados de morfologías variadas (flecha). LPP.

b. Mf.9. Fragmento de coprolito (c) de bóvido. Obsérvese la articulación de los fitolitos en su interior. LPP.

c. Mf.9. Imagen igual (b) en LPX.

d. Mf.10. Microestructura laminar en un fragmento de costra sedimentaria. LPP.

e. Mf.9. Capas laminares compactadas formadas por fitolitos de sílice con una masa basal fina organofosfatada. LPP.

f. Mf.9. Detalle de los fitolitos de sílice. LPP.

Figure 11. Stabling area. CS.VIII. (Early Postcardial Neolithic).

a. Mf.9. Layer of disarticulated silica phytoliths, varied morphologies (arrow). PPL.

b. Mf.9. Fragment of bovine excrement. Note the articulation of phytoliths inside. PPL.

c. Same as (b) in XPL.

d. Mf.10. Platy microstructure in a fragment sedimentary crust. PPL.

e. Mf.9. Compact laminar layers formed by silica phytoliths with a fine organophosphate groundmass. PPL.

f. Mf.9. Detail silica phytoliths. PPL. 
Bergadà, M.M., et al., 2018. Procesos deposicionales y antrópicos en el registro... Boletín Geológico y Minero, 129 (1/2): 251-284

dos orgánicos que pueden causar la disolución de minerales solubles en condiciones ácidas como las esferolitas de calcio fecales (Milek, 2012 y Shahack-Gross, 2011).

Este proceso explicaría las acumulaciones secundarias de $\mathrm{CaCO}_{3}$ en forma de micrita en huecos y alrededor de los agregados.

f) Limos arenosos con cantos y agregados excrementales removilizados

Se distingue en la mf. 7 de CS.VI (Tabla 6). Es resultado de un proceso detrítico coluvional de intensidad baja pero con la suficiente capacidad para arrastrar algunos componentes de microfacies anteriores, como serían los agregados excrementales que poseen las mismas características que en las microfacies anteriormente citadas y aparecen con morfologías subredondeadas y con distintas orientaciones $e$ incluso inclinadas o verticales.

Los procesos de disolución son importantes en restos óseos y en el material calizo.

g) Limos arenosos con movilización y acumulación de arcillas

Está representado por las microfacies 6 y 5 (CS.V.1) y 3 y 2 (CS.III) (Tabla 7).

Las microfacies que se localizan en ambos niveles se han originado por procesos coluvionales de débil intensidad durante un periodo de tiempo en que han quedado en superficie.

Las $\mathrm{mfs} .5$ y 2 se distinguen por una serie de rasgos que irían asociados a procesos de lavado (eluviación) como son: pérdida de material fino de la masa basal y trazas de disolución en el material calizo y en los huesos. En los huesos se manifiesta por los contornos subredondeados, el aumento de la porosidad y la coloración amarilla pálida en LPP que sería resultado en mayor o menor grado de la pérdida del compuesto organo-mineral que lo forma (Hedges and Millard, 1995; Polo Díaz, 2010). En cambio, las mfs. 6 y 3 se caracterizan por la acumulación de finos (iluviación), arcillas mayoritariamente en forma de revestimientos en los hue$\cos$ y también en forma de rellenos no laminados pero con dominios orientados. Las condiciones son propias de ambientes húmedos (presencia de agua) y descarbonatados.

h) Limos arcillosos con nódulos criptocristalinos fosfatados

Esta microfacies está representada por la 1 de CS.I. (Tabla 7). Está formada por una sedimentación detrítica coluvional junto a huesos, carbones y fragmentos cerámicos y nódulos de fosfato -apatito- procedente de acumulaciones biogénicas como guano o posiblemente asociados a desechos humanos (Karkanas and Goldberg, 2010).

\section{Discusión}

\section{Formación, procesos deposicionales y postdeposicio- nales}

Los procesos deposicionales de origen detrítico que originan el relleno de la Cova de Can Sadurní son los siguientes tipos:

- Solifluidales

- Coluvionales

- Arroyadas difusas

a) Procesos solifluidales

Los procesos solifluidales se localizan en la secuencia epipaleolítica y mesolítica - CS XIV (mfs. 26 y 25) y CS XIII (mfs. 24 y 23). Se distinguen principalmente desde el punto de vista estratigráfico y sedimentario por presentar una orientación de los cantos paralela a la pendiente del depósito debido al movimiento en masa (Bertran and Texier, 1999). También se localizan, principalmente en CS. XIII, episodios con cantos con otros en que dominan limos arcillosos, según Bertran and Coutard (2004) son propios del avance del frente de la colada que sepulta los materiales de los niveles superiores que serían los primeros en desplazarse.

Desde el punto de vista micromorfológico, se observan rasgos distintivos en este tipo de procesos:

- CS.XIV (mfs. 26 y 25) caracterizadas por microestructura vesicular, trazas de iluviación de arciIlas con dominios orientados en huecos, disolución del material calizo y óseo, rasgos indicadores de unas condiciones de humedad oscilante propias de estos medios.

- CS.XIII (mfs. 24 y 23) se distingue especialmente en la mf. 23 por una microestructura granular, con ligeras fisuraciones del material detrítico y con cambios de orientación indicadores de unos procesos de hielo-deshielo (Van Vliet-Lanoë, 2010). Estas características indican un cambio importante en las condiciones ambientales de la cueva, que, sin duda, sufrieron los efectos de las heladas una vez se había ocupado la cavidad.

b) Procesos coluvionales

Son los responsables de la mayor parte del registro sedimentario detrítico del yacimiento. Se distinguen dos tipos y en ambos se localizan aportes de origen antrópico: 
- coluviones con flujos densos en los cuales domina la fracción de bloques y cantos

- coluviones no laminados donde predomina la matriz limo arcillosa en relación a la fracción gruesa

Los depósitos de coluviones con flujos densos se desarrollan principalmente en los niveles: CS.XII (Neolítico antiguo cardial), CS.IX (Neolítico postcardial inicial) y CS.VII (Neolítico medio postcardial); en otros quizás su extensión no abarcó la totalidad de la cavidad y el tamaño de la fracción disminuye considerablemente como es CS.V.2 (Neolítico final/Calcolítico) y CS.IV.2 (Bronce inicial).

Este material detrítico, bloques y cantos, procede del colapso exterior y provoca el cambio de la morfología del depósito ya que origina un retroceso de la visera de la cavidad. Hay numerosos factores que pueden provocar dichos episodios tanto de una forma continua o repetitiva (hielo-deshielo, alteración-disolución, variación estacional de la presión de agua intersticial) o bien de forma aleatoria (seísmo, episodios Iluviosos excepcionales...) (Bertran et al., 2004). En nuestro caso resulta muy difícil discernir qué tipo de proceso desencadena la formación de dichos derrubios; ya que, prácticamente la mayoría forman parte del relleno coluvional. De todas formas nos planteamos como hipótesis que podrían ser resultado de procesos denudativos de una fase anterior de alteración, formación de dolinas de hundimiento, evolución en profundidad del lapiaz y disolución muy intensa de las planicies de caliza del techo del conducto de la cavidad en unas condiciones mucho más húmedas y templadas que las actuales. EI lapiaz del sector presenta dos modelados superpuestos, el más antiguo en condiciones pedológicas, bajo cobertura de potentes suelos con gran actividad húmica y de las raíces con perforaciones cilindroideas (rundkarren y klutftkarren) y otro más moderno bajo condiciones aéreas con microcrestas y formas de arroyada (rillenkarren). La evolución de un tipo al otro obedece a la desaparición de la cubierta forestal y la denudación de los suelos edáficos, esto se puede producir por deforestación ligada, o no, a cambios climáticos, es decir al cambio de una fase biostásica a una rexistásica.

Este tipo de aporte se inicia en CS.XII lo que implicó la formación del cono de deyección y la entrada de materiales detríticos en etapas posteriores.

Desde el punto de vista micromorfológico se caracteriza por una masa basal rica en fracción gruesa, de escasa cohesión interna en la cual aparecen mezclados restos óseos, malacológicos, carbones, elementos cerámicos y algunos pocos agregados excrementales de ovicaprinos. La microestructura es granular/de bloques subangulares, con trazas de rotación del material y una débil clasificación, rasgos característicos de estos medios (Bertran and Texier, 1999; Karkanas and Goldberg, 2013).

En los aportes coluvionales no laminados, en los cuales domina la matriz fina, limoarcillosa, $y$ en otros hay un aumento importante de la fracción arenosa, junto a algunos cantos y en ocasiones con algún bloque disperso. Desde el punto de vista micromorfológico se caracterizan por presentar una microestructura masiva/de bloques subangulares con una separación muy fina entre los agregados, trazas propias de estos contextos (Mücher et al., 2010). También aparecen componentes de origen antrópico dispersos por la masa basal.

Algunos aportes son de débil intensidad, en los cuales la actividad humana, principalmente pastoril, queda mejor reflejada y la removilización de sus componentes es menor. Es el caso de CS. XI (mf. 20, Neolítico antiguo cardial final), CS.X (mfs. 18 y 19, Neolítico epicardial), CS.VIII (mf. 12, Neolítico postcardial inicial) y, en cambio, otros en los cuales hay un aumento de la fracción arenosa, los componentes antrópicos aparecen menos conservados y removilizados como en CS.XI (mfs. 21 Neolítico antiguo cardial final), CS.V (mfs. 5 y 6, Neolítico final/Calcolítico) y CS. III (mfs. 2 y 3, de época Ibero-Romana) y, en ocasiones, presentan contactos erosivos como en CS.VI (mf.7, Neolítico medio postcardial).

Algunos de estos aportes como CS.IV.1 (mf. 4, Bronce final) aparecen con una masa basal más arcillosa y con un aumento de la porosidad de tipo vesicular indicadora en este caso de licuefacción, con gran contenido hídrico (Bertran and Texier, 1999).

En el nivel más reciente CS.I (mf. 1, época Romana bajo imperial) del registro, el aporte coluvional aparece mezclado con nódulos de fosfato probablemente de origen excremental o de las propias actividades humanas; aunque es un episodio con intrusiones relativamente recientes.

Entre los rasgos edáficos más comunes de este tipo de depósitos se hallan:

- la eluviación/iluviación de arcillas. 
Principalmente se localiza de forma generalizada el fenómeno de iluviación que es propio de este tipo de contexto donde el agua se infiltra y conlleva un arrastre de material fino (arcilla) y seguidamente se dan periodos de sequedad, en los cuales las arcillas quedan retenidas en los huecos de los niveles inferiores (Fernández et al., 2015). El fenómeno de eluviación de arcillas, proceso de lavado, sólo se ha localizado en la mf. 5 de CS.V (Neolítico final/Calcolítico) y en la mf. 2 de CS.III (época Ibero-Romana).

- rasgos de hidromorfismo. Se manifiestan en nódulos de óxidos e hidróxidos de hierro y en pocas ocasiones de manganeso, con especial importancia en la secuencia del Neolítico antiguo cardial final hasta el Neolítico postcardial (CS.XI, X y en la mf. 12 de CS.VIII), indicadores de saturación de agua principalmente de forma temporal, también coincide con el incremento de actividad pastoril en el interior de la cueva.

c) Arroyadas difusas

Este proceso no es generalizado y se localiza en las mfs. 10 y 8 de CS.VIII (Neolítico postcardial inicial) caracterizado por una sedimentación de arcillas limosas con arenas de muy débil energía; en la muestra 27 en el cuadro E-6 (mf. 10) la arroyada es más activa con la formación de costras sedimentarias.

\section{Procesos antrópicos}

La sedimentación generada por la actividad humana está estrechamente relacionada en la Cova de Can Sadurní con las prácticas de estabulación de animales (ovicaprinos y ganado bovino). Somos conscientes que es difícil establecer consideraciones de este tipo principalmente a partir del análisis micromorfológico del sondeo; pero, creemos que puede ayudar a plantear una serie de hipótesis para el desarrollo de las investigaciones en un futuro inmediato.

Los primeros indicios se constatan en el Neolítico antiguo cardial (CS.XII, capa 18). Se localizan de forma muy dispersa y no muy numerosa componentes diagnósticos de esta actividad (fitolitos de sílice, agregados excrementales sin trazas de combustión y esferolitas de calcio fecales) que nos hace plantear que se haya dado alguna estabulación de ovicaprinos de forma puntual en la cavidad, que coincidiría con otros registros mediterráneos de cronologías similares (Angelucci et al., 2009). También hay que añadir que las reactivaciones coluvionales y el uso sepulcral de la cueva durante este periodo pudieron contribuir a la dispersión de los restos de dichas ocupaciones.
Durante el Neolítico antiguo cardial final (CS.XI, capas 17 y 16) se incrementa la presencia de dichos componentes aunque se localizan dispersos; algunos de los excrementos aparecen con ligeras trazas de combustión. Los aportes sedimentarios son de menor intensidad, lo cual favorece su conservación en el registro sedimentario.

Es durante el Neolítico antiguo epicardial (CS.X, capas $15,14,13$ y 12) cuando se intensifican dichas prácticas. Se constata en general, una disminución de los aportes coluvionales y un aumento de componentes propios de actividad pastoril, llegando a documentarse en contacto con la fase postcardial, algunas áreas con trazas de combustión. Este tipo de depósito también se ha descrito en otros registros mediterráneos neolíticos en cuevas (Angelucci et al., 2009; Boschian, 2006; Boschian and Miracle, 2007); en los cuales, se intercalan capas con combustiones con otras parcialmente sin quemar y a menudo con material arqueológico. Aunque por el momento su interpretación es compleja, algunos creen que son resultado de la alteración y pisoteo de zonas de estabulación no quemadas o parcialmente quemadas (Boschian, 2006), también cómo producto de combustiones muy irregulares de dichas áreas (Brochier, 2002) o de actividades de tipo doméstico entre episodios de tipo redil o de manera simultánea a esta actividad pastoril (Polo Díaz, 2010). En nuestro caso, se documenta en este periodo en las mfs. 19 y 18 un incremento considerable de restos excrementales $y$ vegetales con trazas de combustión; pero, no en su posición original probablemente fruto de removilizaciones por aportes sedimentarios y también antrópicos. En algunos sectores aparecen in situ, como en las $\mathrm{mfs} .17,16$ y 15 , en las cuales aparecen con trazas evidentes de combustión. En Can Sadurní por el momento sólo se localizan tres tipos de microfacies, tal cómo hemos tratado con anterioridad en el apartado d) Acumulaciones excrementales $y$ vegetales mineralizados y carbonizados, la microfacies oscura (mf. 17) correspondería a excrementos que quedaron en superficie y de ahí el hecho de que se constaten trazas de actividad biológica y luego se produciría la quema. A continuación se localizarían las mfs. 16 (carbones con estructura leñosa) y 15, grisácea (cenizas de vegetales leñosos) correspondientes a combustiones a temperaturas más elevadas y aireadas especialmente en la mf. 15.

El funcionamiento de dichas microfacies podría corresponder, según Angelucci et al., (2009), Macphail et al., (1997) y Polo Díaz, (2010), a que una vez los animales abandonan la cavidad los residuos excrementales quedarían expuestos en superficie y posteriormente se produciría la quema a una tempe- 
Bergadà, M.M., et al., 2018. Procesos deposicionales y antrópicos en el registro... Boletín Geológico y Minero, 129 (1/2): $251-284$

ratura baja y en un medio reductor. La presencia de una capa superior formada prácticamente por vegetales leñosos y por algunos excrementos podría ser explicada por la acumulación de ramas procedentes de la estructura del establo o bien restos del ramón (ramas de árboles que se habrían recolectado para alimentar al ganado especialmente en los meses invernales), como sugieren los estudios arqueobotánicos (Antolín, 2013; Antolín and Jacomet, 2015). En tales casos, la combustión sería en un ambiente más ventilado y a una temperatura más elevada. El motivo de estas prácticas de quema quizás se encuentra en una necesidad de sanear el lugar una vez se reinicie la ocupación tal cómo se ha documentado en otros registros (Angelucci et al., 2009; Bergadà et al., 2005a; Bergadà et al., 2005b; Courty et al., 1991; Macphail et al., 1997; Polo Díaz, 2010 y Polo Díaz et al., 2014).

Un aspecto interesante es la presencia de vivianita (fosfato de hierro) en el depósito. Tal cómo hemos tratado anteriormente, para su formación es imprescindible un ambiente reductor de saturación de aguas con un gran contenido orgánico que en nuestro caso procede principalmente de los excrementos; también nos planteamos que hayan contribuido los líquidos procedentes de la excreción de los animales estabulados.

El hecho de que sólo se localicen estas microfacies en un ámbito de la cavidad puede responder también, tal cómo hemos documentado en la M.24, a procesos erosivos del nivel suprayacente correspondiente a CS.IX.

Posteriormente, durante el Neolítico postcardial inicial correspondiente a CS.VIII (capa 11) se utiliza de nuevo la cavidad con dicha finalidad. La sedimentación detrítica disminuye notablemente y aparecen dos tipos de registros:

- Acumulaciones excrementales y vegetales mineralizados y carbonizados se localizan en el inicio de esta etapa cronocultural y presenta similares microfacies, componentes y trazas a las que hemos tratado en la etapa del Neolítico epicardial quizás la diferencia estriba es que en esta etapa las trazas de pisoteo son más evidentes.

- Capas de fitolitos y excrementos organofosfatados. Se distinguen por la presencia de capas compuestas por fitolitos de morfologías variadas en disposición horizontal y subhorizontal y por excrementos. Por la composición de los mismos algunos podrían corresponder muy probablemente a ganado bovino y otros a ovicaprinos. En general, a excepción de la mf. 9 que está in situ, el resto presenta cierta removi- lización debido a las arroyadas difusas, al efecto de pisoteo y a la actividad biológica que se acentúa debido al gran contenido de materia orgánica que constituye una buena fuente de nutrientes para la fauna del suelo. Este alto contenido orgánico conllevaría una cierta acidez en el medio y podría ser la causa de la disminución o escasez de esferolitas fecales de calcio en los excrementos y en la matriz. Se detectan también, al igual que en el periodo Epicardial, fases de abandono con la presencia muy esporádica de fragmentos de cáscara de huevo indicadores de nidificación de aves en la cavidad. En definitiva este tipo de acumulación correspondería a un patrón distinto del anterior, con acumulaciones vegetales, excrementales o una combinación de ambas en forma de lecho sin trazas de combustión. No descartamos localizar en el transcurso de las intervenciones arqueológicas áreas con trazas de combustión, cómo las mfs. 14 y 13, nos planteamos, a modo de hipótesis, que las combustiones se darían en aquellas acumulaciones donde hubiera restos leñosos, tal como se registra en las microfacies citadas.

Finalmente se utilizó el ámbito con un fin sepulcral en el cual los inhumados, sector F-9 y G-11, se depositaron directamente en dichas acumulaciones (Edo et al., en prensa a).

Hacia el Neolítico medio postcardial, CS.VI (capa 10), hay una disminución destacable de restos vegetales y también de coprolitos que aparecen muy dispersos por la matriz y adoptan distintas posiciones (verticales, inclinados...); rasgos que nos hacen plantear que procedan del horizonte anterior erosionados por los aportes coluvionales que se dieron en esta fase.

A partir de este horizonte cronocultural, desde el punto de vista microestratigráfico, no se constatan evidencias de actividades pastoriles en la cueva.

\section{Evolución cronoestratigráfica y paleoambiental}

La secuencia sedimentaria se inicia, con un aporte solifluidal, CS,XIV -mfs. 26 y 25- registrado entre $12690-10480$ cal BP/10740- $8530 \mathrm{cal}$ BC con un hiato, tal como se desprende de las dataciones obtenidas (Tabla 1). Por las características del análisis micromorfológico el contexto de dicho aporte sería propio de unas condiciones muy frescas y húmedas. Desde el punto de vista cronoestratigráfico registraría los inicios del Younger Dryas y el Preboreal y culturalmente se atribuye al Epipaleolítico. 
Tras un hiato reaparece la sedimentación generada también por un aporte solifluidal, CS XIII, mfs 24 y 23 correspondiente al Mesolítico de muescas y denticulados, que se situaría en una horquilla entre el 8290 - 8010 cal BP/6340 - 6060 cal BC, en un medio donde las condiciones no son tan húmedas con leves procesos de crioturbación, lo que nos indicaría un descenso de la temperatura, podría estar relacionado con el evento 8.2 Ka cal BP de la cronozona Atlántico caracterizado por un aumento de la aridez y por unas condiciones más frías (Bond et al., 1997).

Tras una interrupción, se reanuda la sedimentación con CS.XII, correspondiente al Neolítico antiguo cardial. Este aporte es consecuencia de un colapso que conlleva un retroceso importante de la visera de la cavidad. Dicho proceso implica la formación del cono de deyección y la entrada de materiales detríticos en masa, con bloques y cantos, con reactivaciones coluvionales que se manifiestan tanto por las evidencias del análisis micromorfológico como por la disposición del material arqueológico y humano (Edo et al., en prensa b). En la ocupación en la cueva, fechada en una horquilla temporal que con la máxima probabilidad se extiende entre 7430 y 7250 cal $\mathrm{BP} / 5480$ y $5300 \mathrm{cal} B C$, se detecta un inicio de las actividades pastoriles y un uso sepulcral.

De lo expuesto se puede deducir que durante este periodo de inicios del Neolítico, correspondiente a la parte media del periodo Atlántico, se activan los procesos de movimientos de masa y coluviones originando rellenos; depósitos también contrastados en otras áreas de la vertiente mediterránea (Fumanal, 1995).

Tras una breve interrupción, se reanuda la sedimentación detrítica con aportes coluvionales de menor intensidad, CS XI -mfs. 21 y 20-, datada entre $7200-6650$ cal BP/5250 - 4700 cal BC.

Se detecta un incremento de procesos de hidromorfía reflejo posiblemente de saturación de aguas no permanente; quizás pueda establecerse una correlación con los datos proporcionados por los análisis palinológicos en los cuales hay indicadores de una expansión de humedales en las llanuras deltaicas del Llobregat y del Besós (Riera et al., 2007).

Reaparece el aporte detrítico coluvional pero también de poca intensidad, CS.X, aunque con alguna reactivación fechada entre 6930 - 6710 cal BP/4980 4760 cal BC, la actividad pastoril en la cavidad se acentúa con la presencia de niveles in situ de rediles, $\mathrm{mfs}$. 17, 16 y 15 . Aspectos que denota una interrupción en la sedimentación detrítica y al mismo tiempo una estabilidad en el medio. Se le atribuye al Neolítico epicardial y se situaría en el tramo superior del Atlántico. Las condiciones hidromórficas se acen- túan en un medio más reductor debido probablemente a la intensificación de animales estabulados en la cueva.

Posteriormente se produce otro colapso exterior que cambiará de nuevo la morfología de la cavidad, dichos materiales detríticos configuraran gran parte de los aportes de CS.IX, que erosionará en algunos sectores parte del nivel subyacente. Este episodio está fechado entre la horquilla de 6870 - 6310 cal BP/4920 - 4360 cal BC correspondiente al Neolítico postcardial inicial.

La secuencia continúa, dentro de la misma etapa cultural, con CS.VIII con una sedimentación muy dinámica entre aportes sedimentarios antrópicos de rediles in situ, mfs. 14 y 13,11 y 9 con aportes detríticos coluvionales de poca energía, mf. 12, y de arroyadas difusas mf. 10 y mf. 8. Por dichos episodios deducimos que es una fase en que predomina una estabilidad en el medio, fechada entre $6570-5960 \mathrm{cal}$ BP/4620 - 4010 cal BC. Las condiciones hidromórficas aún están presentes pero no tan acentuadas como en la etapa anterior. También se utilizó la cavidad con un uso funerario.

Tras una breve interrupción, finales del periodo Atlántico y comienzos del Subboreal, se registra un nuevo depósito con un dominio de la sedimentación detrítica, CS.VII $(6240-5740$ cal BP/4290 - 3790 cal BC) y CS.VI (6190 - $5940 \mathrm{cal} \mathrm{BP/4240} \mathrm{-} 3990 \mathrm{cal} \mathrm{BC),} \mathrm{se}$ distingue por unos aportes, también coluvionales $y$ que erosionaron parte del nivel subyacente. Culturalmente se atribuye al Neolítico medio postcardial y también tiene una utilización sepulcral. Los resultados del análisis aquí presentado indican que durante esta fase la actividad pastoril en Can Sadurní prácticamente no se desarrolla o disminuye considerablemente. Nuestra interpretación podría verse apoyada por los datos palinológicos obtenidos en zonas cercanas que demuestran que los incendios son más esporádicos y que los indicadores nitrófilos relacionados con el pastoreo decrecen (Riera et al., 2007).

La secuencia continúa en el Subboreal, en la horquilla de $5250-4340$ cal BP/3300 - 2390 cal BC, en CS.V, correspondiente al Neolítico final/Calcolítico, los aportes en masa son de menor envergadura y al final del registro se detecta una alternancia de fases húmedas (mf. 5) con fases más secas (mf. 6).

Tras una interrupción se reanuda la sedimentación con CS.IV.2 atribuida al Bronce inicial datada en 3950 - 3200 cal BP/2000-1250 cal BC y enmarcada en pleno Subboreal, también resultado de procesos clásticos no tan importantes como en anteriores niveles. A continuación, la secuencia CS.IV.1, atribuida al Bronce final (3340 -2830 cal BP/1390 - 880 cal BC) viene caracterizada por un registro con una sedimen- 
tación coluvional con un gran contenido de agua, en un medio muy húmedo; condiciones acordes para este periodo de finales del Subboreal al Subatlántico con las propuestas en otros registros peninsulares (Peña et al., 2005; Pérez-Lambán et al., 2014).

Los aportes coluvionales también están bien representados en el Subatlántico con CS.III, de época Ibero-Romana (2290 - 2040 cal BP/340 - 90 cal BC), especialmente en las mfs. 3 y 4 en que también se documentan alternancias de fases húmedas con otras fases más secas. Esta etapa está bien caracterizada desde el punto de vista geoarqueológico y geomorfológico principalmente en la Cordillera Ibérica por el inicio de procesos erosivos en las laderas y la acumulación correlativa en conos y fondos de valle que alcanzan una gran potencia (Peña et al., 2005).

EI registro sigue con CS.II y I de época Romana, siglo II - IV d.C., donde aparecen aportes detríticos junto a una actividad de origen biogénico o antrópico indicadora de una fase de estabilidad que culmina la sedimentación detrítica en Can Sadurní. Finalmente, CS.0, una débil costra carbonatada muy probablemente de época subactual.

\section{Conclusiones}

El estudio microestratigráfico de la Cova de Can Sadurní nos ha permitido precisar la secuencia sedimentaria del yacimiento distinguiendo los aportes detríticos y los aportes generados por la actividad humana de tipo pastoril. La secuencia con mayor resolución que nos ofrece el yacimiento es la neolítica con una tasa de sedimentación detrítica y antrópica importante acompañada de una amplia batería de dataciones radiocarbónicas. Su análisis nos ha permitido contrastar la alternancia de episodios acumulativos (movimientos de masa y coluviones con ápice en la apertura de la cavidad al exterior y que se distribuyen hacía el interior en abanico, con pendientes que van disminuyendo progresivamente) con los episodios de estabilidad en el medio coincidentes con la mayor actividad pastoril registrada en el yacimiento durante el Neolítico epicardial y postcardial inicial.

Las fases de redil identificadas en la Cova de Can Sadurní revelan el uso de la cavidad como un recinto principalmente de ovicápridos pero muy posiblemente también de bóvidos. La quema de los residuos es recurrente aunque no en todo el ámbito de la cavidad; cabe señalar que los procesos coluvionales y de arroyada que afectaron durante y después de la ocupación han alterado dichos depósitos; así como la actividad sepulcral que tuvo la cavidad en algunas etapas.

A partir del Neolítico medio postcardial hay una dis- minución de los aportes generados por la estabulación de animales en la cavidad posiblemente por un cambio de estrategia del pastoreo en la zona. La secuencia continúa con procesos acumulativos detríticos de menor envergadura hasta época Romana tardía.

En definitiva, creemos que la Cova de Can Sadurní abre nuevas vías para el estudio de la evolución sedimentoclimática del Holoceno y de las estrategias pastoriles en el macizo del Garraf.

\section{Agradecimientos}

Quisiéramos agradecer a Pepa Villalba y Anna Blasco por su ayuda en la realización de los muestreos y por toda la información facilitada. También expresamos nuestro reconocimiento a los Centros Científicos y Tecnológicos de la Universitat de Barcelona (CCiT-UB) por la utilización del Servicio de Microscopía electrónica. Esta investigación se enmarca en los proyectos HAR2014-55131 del Ministerio de Educación y Ciencia (MEC), 2014/100780 de la Generalitat de Catalunya y el Grup de Recerca de Qualitat SRG2014-108.

\section{Referencias}

Angelucci, D.E., Boschian, G., Fontanals, M., Pedrotti, A. and Vergés, J.M. 2009. Shepherds and karst: the use of caves and rock-shelters in the Mediterranean region during the Neolithic. World Archaeology, 41 (2), 191-214.

Antolín, F. 2013. Of cereals, poppy, acorns and hazelnuts. Plant economy among early farmers (5500-2300 cal BC) in the NE of the Iberian Peninsula. An archaeobotanical approach. Dept. de Prehistoria, Universitat Autònoma de Barcelona, http://hdl.handle.net/10803/128997.

Antolín, F., Ache, M., Bergadà, M.M., Blasco, A., Buxó, R., Edo, M., Gibaja, J.F., Mensua, C., Palomo, A., Piqué, R., Ruiz, J., Saña, M., Verdún, E. and Villalba, M.J. 2011. Aproximació interdisciplinària a l'acció del foc en les inhumacions i aixovars del Neolític antic cardial de Can Sadurní (Begues, Baix Llobregat). In: Blasco, A., Edo, M., Villalba, M.J. (eds.), La Cova de Can Sadurní i la Prehistòria de Garraf. Recull de 30 anys d'investigació, Begues, desembre 2008, EDAR, Milano, 151-158.

Antolín, F. and Jacomet, S. 2015. Wild fruit use among early farmers in the Neolithic (5400-2300 cal BC) in the northeast of the Iberian Peninsula: an intensive practice? Vegetation History and Archaeobotany, 24, 19-33.

Benyarku, C.A. and Stoops G. 2005. Guidelines for preparation of rock and soil thin sections and polished sections. Department of Environment and Soil Science, University of Lleida, Lleida, $84 \mathrm{pp}$.

Bergadà, M.M. 1998. Estudio geoarqueológico de los asentamientos prehistóricos del Pleistoceno Superior y el Holoceno inicial en Catalunya. BAR International Series 742. Archaeopress, Oxford, 267 pp. 
Bergadà, M.M., Cebrià, A. and Mestres, J. 2005 a. Prácticas de estabulación durante el Neolítico antiguo en Cataluña a través de la micromorfología: cueva de la Guineu (Font-Rubí, Alt Penedès, Barcelona). III Congreso del Neolítico en la Península Ibérica, Santander, 187- 96.

Bergadà, M.M., Guerrero, V.M. and Ensenyat, J. 2005 b. Primeras evidencias de estabulación en el yacimiento de Son Matge (Serra de Tramuntana, Mallorca) a través del registro sedimentario. Mayurqa, 30, 153-180.

Bergadà, M.M. and Cervelló, J.M. 2011. Estratigrafia, micromorfologia paleoambient de la Cova de Can Sadurní (Begues, Baix Llobregat) des dels $c$. 11.000 fins els 5.000 anys B.P. In: Blasco, A., Edo, M., Villalba, M.J. (eds.), La Cova de Can Sadurní i la Prehistòria de Garraf. Recull de 30 anys d'investigació. Begues, desembre 2008, EDAR, Milano, 97-108.

Bertran, P. and Coutard, J.P. 2004. Solifluxion. In: Bertran, P (ed.), Dépôt de pente continentaux dynamique et faciès. Quaternaire, (1), 80-109.

Bertran, P., Francou, B. and Texier, J.P. 2004. Éboulisation, Éboulement. In: Bertran, P (ed.), Dépôt de pente continentaux dynamique et faciès. Quaternaire, 1, 29-43.

Bertran, P. and Texier, J.P. 1999. Facies and microfacies of slope deposits. Catena, 35, 99-121.

Blasco, A., Edo, M. and Villalba, M.J. 2005 a. Cardial, Epicardial y Postcardial en Can Sadurní (Begues, Baix Llobregat). El largo fin del Neolítico antiguo en Cataluña, III Congreso del Neolítico en la península Ibérica, Santander, 867 - 876.

Blasco, A., Edo, M. and Villalba, M.J. 2005 b.Primeros datos sobre la utilización sepulcral de la cueva de Can Sadurní (Begues, Baix Llobregat) en el Neolítico Cardial, III Congreso del Neolítico en la península Ibérica, Santander, 625-633.

Bond, G., Showers, W., Cheseby, M., Lotti, R., Almasi, P., Demenocal, P., Priore, P., Cullen, H., Hajdas, I. and Bonani, G. 1997. A pervasive millenial-scale cycle in North Atlantic Holocene and glacial climates. Science, 278, 1257-1266.

Boschian, G. 2006. Geoarchaeology of Pupicina cave. In: Miracle, P.T. and Forenbaher, S. (eds.), Prehistoric Herders in Istria (Croatia): The Archaeology of Pupicina Cave (1). Archaeological Museum of Istria, Pula.

Boschian, G. and Miracle, P.T. 2007. Shepherds and caves in the karst of Istria (Croatia). Atti Soc. tosc. Sci. nat., Mem., Serie A, 112, 173-180.

Brochier, J.E. 1996. Feullies ou fumiers? Observations sur le rôle des opusieres sphérolitiques dans l'interprétation des dépôts archéologiques holocènes. Anthropozoologica, 24, 19-30.

Brochier, J.E. 2002. Les sédiments anthropiques: méthodes d'étude et perspectives. In: Miskovsky, J.C. (ed), Géologie de la Préhistoire: méthodes, techniques, applications, 2nd ed. Geopré., Paris, 453-477.

Bullock, P., Fedoroff, N., Jongerius, A., Stoops, G. and Tursina, T. 1985. Handbook for soil thin section description. Waine research publ., Wolverhampton, $152 \mathrm{pp}$.

Canti, M.G. 1997. An investigation of microscopic calcareous spherulites from herbivore dungs. Journal of Archaeological Science, 24, 219-231.
Canti, M.G. 2003. Aspects of the chemical and microscopic characteristics of plant ashes found in archaeological soils. Catena, 54, 339-361.

Courty, M.A. 2001. Microfacies analysis assisting archaeological stratigraphy. In: Goldberg, P., Holliday, V.T. and Reid Ferring, C. (ed.), Earth Sciences and Archaeology. Kluwer Academic, 205-239.

Courty, M.A., Goldberg, P. and Macphail, R.I. 1989. Soils and micromorphology in archaeology. Cambridge University Press, $344 \mathrm{pp}$.

Courty, M.A., Macphail, R.I. and Wattez, J. 1991. Soil micromorphological indicators of pastoralism; with special reference to Arene Candide, Finale Ligure, Italy, Rivista di Studi Liguri, A. LVII 1-4, 127-150.

Dabrio, C.J. and Hernando, S. 2003. Estratigrafía. Colección Geociencias. Facultad de Ciencias Geológicas. Universidad Complutense de Madrid, Madrid, 382 pp.

Daura J, Sanz M., Fornós J.J, Asensio A. and Julià R. 2014. Karst evolution of the Garraf Massif (Barcelona, Spain): Doline formation, chronology and archaeo-palaentological archives. Journal of Cave and Karst Studies, 76 (2), 69-87.

Dorronsoro, B., Aguilar, J., Dorronsoro-Díaz, C., Stoops, G., Sierra, M., Fernández, J. and Dorronsoro-Fdez, C. 2015. HydroSols. Hidromorfía en suelos. <<http://www.edafologia.net/hidro/index.htm >> (Accesed 2/03/2015).

Durand, N., Curtis, H. and Canti, M.G. 2010. Calcium carbonate features. In: Stoops, G., Marcelino, V., Mees, F. (eds.), Interpretation of micromorphological features of Soils and Regoliths. Elsevier, Amsterdam, 149-194.

Edo, M., Antolín, F., Martínez, P., Castellana, C., Bardera, R., Saña, M., Bergadà, M.M., Fullola, J. M., Barrio, C., Fierro, E., Castillo, T. and Fornell, E. en prensa a. Cueva de Can Sadurní (Begues, Barcelona). Hacia la definición del modelo funerario en cueva para el Neolítico Medio I del nordeste peninsular. In: Gibaja, J.F., Subirà, M.E., Martín, A., Mozota, M., Roig, J. Mirando a la Muerte. Las prácticas funerarias durante el neolítico en el noreste peninsular. E-ditArx - Publicaciones Digitales, Castellón.

Edo M; Antolín, F; Martínez, P; Villalba, M.J; Fullola, J.M: Bergadà, M.M; Saña, M; Verdún, $E$; FernándezDomínguez, E; Gamba, C; Arroyo-Pardo, E; Ache, M; Gibaja, J.F; Palomo, A; Clop, X. and Manen, C, en prensa b. El episodio funerario del neolítico antiguo cardial pleno de la cueva de Can Sadurní (Begues, Barcelona). Estado actual de la cuestión. In: Gibaja, J.F., Subirà, M.E., Martín, A., Mozota, M., Roig, J. Mirando a la Muerte. Las prácticas funerarias durante el neolítico en el noreste peninsular. E-ditArx - Publicaciones Digitales, Castellón.

Edo, M., Blasco, A. and Villalba, M.J. 2011. La cova de Can Sadurní, guió sintètic de la prehistòria recent de Garraf. In: Blasco, A., Edo, M., Villalba, M.J, (eds), La Cova de Can Sadurní i la prehistòria de Garraf. Recull de 30 anys d'investigacions. EDAR. Milano, 13 - 95.

Fernández, F., Dorronsoro-Fdez, C., Aguilar, J., Dorronsoro, B., Stoops, G. and Dorronsoro Díaz, C. 2015. IlluviaSols. El proceso de iluviación de arcilla en los suelos. http:// www.edafologia.net/iluv/index.htm (Accesed 7/03/2015).

Fitzpatrick, E.A. 1990. Micromorfología de suelos. Compañía editorial continental. México, 476 pp. 
Fumanal, M.P. 1995. Los depósitos cuaternarios en cuevas y abrigos. Implicaciones sedimentoclimáticas. El Cuaternario del País Valenciano. Universitat de. València, Valencia, 115-124.

Goldberg, P., Miller, C.E., Schiegl, S., Ligouis, B., Berna, F., Conard, N.C. and Wadley, L. 2009. Bedding, hearths, and site maintenance in the Middle Stone Age of Sibudu Cave, KwaZulu-Natal, South Africa. Archaeological Anthropological Sciences, 1, 95-122.

Hedges, R.E. and Millard, A. R. 1995. Bones and groundwater: towards the modelling of diagenetic processes. Journal of Archaeological Science, 22, 155-164.

ICGC 2005. Mapa geològic comarcal. Baix Llobregat (11). 1:50.000. Mapa geològic continu. Generalitat de Catalunya.

Karkanas, P. and Goldberg, P. 2010. Phosphatic features. In: Stoops, G., Marcelino, V. and Mees, F., (eds), Interpretation of micromorphological features of soils and regoliths. Elsevier, Amsterdam, pp. 521-541.

Karkanas, P. and Goldberg P. 2013. Micromorphology of cave sediments. In: John F. Shroder (editor-in-chief), Frumkin, A. (volume Editor). Treatise on Geomorphology, Vol 6, Karst Geomorphology, Academic Press, San Diego, 286-297.

Macphail, R.I., Courty, M.A., Hather, J. and Wattez, J. 1997. The soil micromorphological evidence of domestic occupation and stabling activities. Memorie dell'Instituto Italiano di Paleontologia umana, V, 53 - 86.

Macphail, R.I., Cruise, G.M., Allen, M.J., Linderholm, J. and Reynolds, J. 2004. Archaeological soil and pollen analysis of experimental floor deposits; with special reference to Butser Ancient Farm, Hampshire, UK. Journal of Archaeological Science, 31, 175-191.

McGowan, G. and Prangnell, J. 2006. The significance of vivianite in archaeological settings. Geoarchaeology: An International Journal, 21 (1), 93-111.

Mentzer, S. M. 2014. Microarchaeological Approaches to the Identification and interpretation of combustion features in prehistoric archaeological sites. Journal of Archaeological Method Theory, 21, 616-668.

Milek, K.B. 2012. Floor formation processes and the interpretation of site activity areas: An ethnoarchaeological study of turf buildings at Thverá, northeast Iceland. Journal of Anthropological Archaeology, 31, 119 - 137.

Miller, C., Conard, N.J., Goldberg, P., and Berna, F. 2009. Dumping, sweeping and trampling: Experimental micromorphological analysis of anthropogenically modified combustion features. P@lethnologie, 2009, 25-37.

Mücher, H., Van Steijn, H. and Kwaad, F. 2010. Colluvial and mass wasting deposits. In: Stoops, G., Marcelino, $V$ and Mees, F., (eds.), Interpretation of micromorphological features of soils and regoliths. Elsevier, Amsterdam, 37- 48.
Nicosia, C. 2008. Micromorphology of some phosphatic inclusions and neoformations of ocurring in archaeological deposits. Frankfurter geowiss. Arbeiten, 30, 8594.

Pagliai, M. and Stoops, G. 2010. Physical and biological surface crust and seals. In: Stoops, G., Marcelino, V. and Mees, F., (eds.), Interpretation of micromorphological features of soils and regoliths. Elsevier, Amsterdam, 419 -440 .

Peña, J.L., Sancho, C., Rubio, V. and Longares, L.A. 2005. Aportaciones desde la geomorfología y la geoarqueología al conocimiento de los paleoambientes holocenos semiáridos del NE de España. In: APG (ed.), A Geografia ibérica no contexto europeo ( $X$ Coloquio Ibérico de Geografía, 22-24 de Setembro de 2005).Universidade de Évora.

Pérez-Lambán, F., Peña-Monné, J.L., Fanlo-Loras, J., PicazoMillán, J. V. Badia-Villas, D, Rubio-Fernández, V., GarcíaGiménez, R. and Sampietro-Vattuone, M. 2014. Paleoenvironmental and geoarchaeological reconstruction from late Holocene slope records (Lower Huerva Valley, Ebro Basin, NE Spain). Quaternary Research, 81 (1), 1-14.

Polo-Díaz, A. 2010. Rediles prehistóricos y uso del espacio en abrigos bajo roca en la Cuenca Alta del Ebro: geoarqueología y procesos de formación durante el Holoceno. Tesis doctoral. Universidad del País VascoEuskal Herriko Unibertsitatea.

Polo-Díaz, A., Martínez-Moreno, J., Benito-Calvo, A. and Mora, R. 2014. Prehistoric herding facilities: site formation and archaeological dynamics in Cova Gran de Santa Linya (Southeastern Prepyrenees, Iberia), Journal of Archaeological Science, 41, 784-800.

Riera, S., Esteve, X. and Nadal, J. 2007. Systèmes d'exploitation et anthropisation du paysage méditerranéen du Néolithique ancien au premier âge du Fer: le cas de la dépression de Penedès (nord-est de la péninsule ibérique). Environnements et cultures à l'âge du Bronze en Europe Occidentale (Actes des congrès nationaux des Sociétés historiques et scientifiques 129e, Besançon, 2004). Editions du CTHS, Paris, 121-141.

Shahack-Gross, R. 2011. Herbivorous livestock dung: formation, taphonomy, methods for identification and archaeological significance. Journal of Archaeological Science, 38, $205-218$.

Stoops, G. 2003. Guidelines for Analysis and Description of Soil and Regolith Thin Section. Soil Science Society of America, lonc, Wisconsin, Madison, 184 pp.

Van Vliet-Lanoë, B. 2010. Frost action. In: Stoops, G., Marcelino, V. and Mees, F., (eds.), Interpretation of micromorphological features of soils and regoliths. Elsevier, Amsterdam, 81-108.

Recibido: mayo 2015

Revisado: enero 2016

Aceptado: marzo 2016

Publicado: marzo 2018 